\title{
Trust transfer and partner selection in interfirm relationships
}

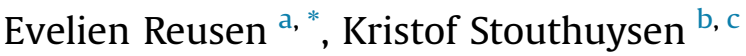 \\ ${ }^{a}$ Rotterdam School of Management, Erasmus University, Burgemeester Oudlaan 50, 3062, PA, Rotterdam, The Netherlands \\ ${ }^{\mathrm{b}}$ Vlerick Business School, Vlamingenstraat 83, 3000, Leuven, Belgium \\ ${ }^{c}$ Vlerick Business School, Naamsestraat 69, 3000, KU Leuven, Belgium
}

\section{A R T I C L E I N F O}

\section{Article history:}

Received 14 March 2017

Received in revised form

23 October 2019

Accepted 30 October 2019

Available online $\mathrm{xxx}$

\section{Keywords:}

Trust transfer

Partner selection

Interfirm relationships

\begin{abstract}
A B S T R A C T
Despite third parties being important conduits of trust, little is known about the mechanisms and conditions relevant to their influence on trust formation and partner selection in interfirm relationships. In this study, we experimentally examine how varying levels of third-party information shape the trust that buyer managers have in a potential supplier firm, and how this trust affects subsequent selection decisions. In addition, we investigate when this information is most influential, by accounting for the moderating impact of the focal firm's own prior experience. As expected, both neutral and favorable third-party information are able to elicit trust, yet with different effects on competence and goodwill trusting beliefs. These trusting beliefs, in turn, are positively associated with the likelihood of the supplier to be selected. Notably, we find third-party effects over and above the effects resulting from own prior experience. Overall, by investigating differences with regard to the origin and content of information and the specific type of trust, this study advances a more nuanced understanding of the partner selection process.
\end{abstract}

() 2019 Elsevier Ltd. All rights reserved.

\section{Introduction}

Studies on the role of management control in mitigating the risks of interfirm relationships suggest that, alongside formal governance and control structures, appropriate partner search and selection is critical for the effective management and success of these relationships (e.g., Dekker, 2008; Dekker \& Van den Abbeele, 2010; Ding, Dekker, \& Groot, 2013; Mahama \& Chua, 2016). The decision-making process associated with selecting a collaboration partner, however, is complex and challenging, especially given the high level of uncertainty and risk associated with entering new partnerships. At relationship inception, performance risk and relational risk are the two primary types of risk that need to be considered (Das \& Teng, 2001; Langfield-Smith, 2008). Whereas performance risk results from uncertainties about the partner's performance, relational risk results from exposure to the partner's potential opportunistic behavior. This brings about the relevance of two trust dimensions, relating to the partner's competencies on the one hand, and the partner's reliability or goodwill on the other hand (e.g., Anderson, Chang, Cheng, \& Phua, 2017; Das \& Teng,

\footnotetext{
* Corresponding author.

E-mail addresses: reusen@rsm.nl (E. Reusen), kristof.stouthuysen@vlerick.com (K. Stouthuysen).
}

2001; Dekker, Sakaguchi, \& Kuwai, 2013; Langfield-Smith, 2008). For the selection process, this implies that evaluation on these dimensions is important.

As has been long contended in the network literature, relevant information on the competencies and reliability of potential partners originates, in part, from third parties (e.g., Baum, Rowley, Shipilov, \& Chuang, 2005; Gulati \& Gargiulo, 1999). In particular, other firms' dealings with a partner constitutes an important indirect channel of information that can be used to evaluate that partner, and to predict the partner's performance and behavior in future interactions. Yet, while accounting scholars have speculated about how third parties may serve as trust intermediaries (e.g., Ding et al., 2013; Mahama \& Chua, 2016), no research to date has modeled and directly assessed the effect of third-party information on the emergence of trust and subsequent partner selection within an interfirm setting. In addition, there exists limited insight into how information originating from third parties interrelates with information from own prior experience. This study seeks to address these gaps and, by doing so, to improve our understanding of the partner selection process.

The study draws on current theoretical understandings of trust cues that are important for interfirm partnering and particularly examines trust transfer as a means for establishing trust. Our focus is on a buyer manager's trust in a potential supplier firm during the 
initial stages of the relationship, when partners are being evaluated and potentially selected. The basic premise behind trust transfer in this context is that, other than based on own prior experience with the supplier, buyer managers' initial trust impressions are based on the cues provided by third parties, such as other buyer firms.

Importantly, however, we argue that third-party influence varies depending on the information content brought by these third parties and the particular type of trust. A crucial difference in the informational signals stemming from third parties lies in whether the outcomes of third-party dealings are known or not. While prior studies mainly suggest that information about the outcomes of other firms' dealings can contribute to perceptions of the partner's trustworthiness (see also, Barrera \& Buskens, 2007; Stewart, 2003), specific outcome information may not always be available. In many instances, one can observe the behavior of other trustors, while their payoffs remain unknown. ${ }^{1}$ This invokes the question of whether the mere knowledge of other firms' dealings, without any information about the outcomes, is sufficient to elicit trust. Therefore, besides situations in which decision-makers are informed about the outcomes obtained by other firms from dealing with the partner, this study also investigates trust problems in which information available is less specific. We further differentiate between the competence and goodwill dimensions of trust, each dimension reflecting a unique perceptual perspective from which managers consider a potential partner, for which third-party information is expected to be differentially informative. In order to more completely grasp the impact of third-party information, we also account for the opportunity of learning from one's own past dealings with the partner, based on the assumption that this changes managers' informational needs and modifies their reliance on third parties.

In our experiment, participants assume the role of a buyer manager in charge of handling collaborative relationships with supplier firms, with information from own firm experience and from third parties being manipulated respectively, in order to assess whether this would influence the level of, both competence and goodwill, trust and, in turn, the likelihood to select. Regarding third-party information, we compare two conditions where information is provided about other firms' prior dealings with a potential supplier, varying the completeness of information by either excluding or including obtained outcomes, to a control condition where no such information is presented. In addition, we examine whether responses to third-party information differ depending on whether positive own firm experience is present, as an alternative information source, or not.

The primary contribution of this study to the accounting literature is an increased understanding of the role of third-party information, distinguishing between relatively neutral (i.e., excluding outcomes) and more specific, pointed information (i.e., including outcomes), in establishing trust and influencing subsequent partner selection. We show that third-party information, depending on its content, triggers different effects on competence and goodwill trusting beliefs. Specifically, the results reveal that simply knowing other firms that trusted the supplier, without any information about the outcomes, is sufficient for the participants' level of competence trust in the supplier to increase. This provides evidence for trust transfer even while excluding a reinforcement statement, namely, that it would lead to desirable outcomes. The

\footnotetext{
${ }^{1}$ For example, from company webpages, press releases or more specific channels such as supplier discovery platforms, one can easily acquire information about potential suppliers' past and current business relationships. While this information reveals something about the extent to which other firms have trusted the supplier, the precise outcomes of these dealings are not publicly available.
}

participants' level of goodwill trust in the supplier, in contrast, is only found to increase when it is known that other firms had good outcomes, and thus the supplier proved to be trustworthy.

Altogether, our findings illustrate that the informational basis on which competence trust and goodwill trust are built is not necessarily the same, although both are shown to be important criteria in partner selection. With this, the study responds to prior research that has called for a more detailed understanding about the antecedents and consequences of trust (e.g., Anderson et al., 2017; Dekker, Sakaguchi, \& Kawai, 2013), as it unravels the process of how information from third parties affects partner selection through the formation of specific trusting beliefs.

By considering the moderating role of direct learning from own experience, this study also sought to shed more light on when thirdparty information is most influential for partner selection. In contrast to prior research that has suggested a substitutional relationship between prior partner experience and the search for information (e.g., Baum et al., 2005; Dekker \& Van den Abbeele, 2010), we do not find that information from own experience weakens the effect of third-party information on the formation of trust. Instead, results indicate that even for buyer managers who are able to rely on their firm's own prior experiences, third-party information is conducive to the perceptions they hold regarding the supplier's trustworthiness, and influences selection decisions accordingly.

Given the common challenges in partner search and selection, this study is also relevant for business practice. As current customers are among the most influential information sources in choosing vendors and business partners alike, this study demonstrates that decision-makers indeed value third-party information as a critical part of their search, evaluation, and decision-making process. Drawing on these insights, there is a clear opportunity for supplier firms to leverage their relationships with third parties. The results of our study not only suggest that displaying information about previous partnerships is a worthy trust-building tactic, but also points up the potential of activating satisfied partners and connecting them with prospective buyers as to promote trust transfer. If done effectively, suppliers are more likely to be seen as trustworthy, creating a competitive edge when it comes to partner selection.

The rest of the paper proceeds as follows. We first discuss the theoretical background and develop the hypotheses. We next describe the experiment and report the results. The final section concludes.

\section{Theory and hypotheses}

\subsection{Trust in interfirm relationships}

Interfirm relationships involve interdependence and firms and their managers must, therefore, depend on others in various ways to accomplish their organizational goals. Several theories have emerged that describe mechanisms for minimizing the risk inherent in such arrangements. Most of these theories, such as transaction cost theory, focus on the design of appropriate contracts as an important governance mechanism. However, as a consequence of complexity and uncertainty, it is usually not feasible to lay down each party's obligations completely and unambiguously in advance, and so most contracts are incomplete (Krishnan, Miller, \& Sedatole, 2011; Vosselman \& Van der MeerKooistra, 2009). Since it is impossible to manage all vulnerabilities through enforceable contracts, firms and their managers rely on trust to facilitate cooperation (Dekker, 2004; Emsley \& Kidon, 2007; Sako, 1992).

Following prior literature, we define trust as a psychological 
state comprising the intention to accept vulnerability based on positive expectations about the motivations or behaviors of another (Mayer, Davis, \& Schoorman, 1995; Rousseau, Sitkin, Burt, \& Camerer, 1998). Based on this notion, trust is often referred to as the perception formed by one party about another party's trustworthiness. Early research on interfirm trust posits that the perceived likelihood that the other party will be trustworthy is based on judgments about its competencies and goodwill (Das \& Teng, 2001; Nooteboom, 1996). Specifically, in line with prior accounting and information systems research (e.g., Anderson et al., 2017; Nicolaou, Sedatole, \& Lankton, 2011), we consider trust as the belief that the other party has beneficial characteristics, and implies favorable perceptions about the exchange partner's competencies (i.e., has the ability to do what the partner needs done), integrity (i.e., is honest and keeps commitments), and benevolence (i.e., is responsive to the partner's interests, not just its own). Combined, perceptions of competence entail attributions regarding the ability of the other party, while perceptions of goodwill entail attributions regarding the integrity and benevolence of the other party. Hence, our definition of interfirm trust encompasses not only concerns about a partner's ability to perform according to agreements, but also its intentions to do so. ${ }^{2}$ Positive expectations along these dimensions provide the foundation for one's willingness to accept vulnerability (McEvily, Perrone, \& Zaheer, 2003; Vosselman \& Van der Meer-Kooistra, 2009), which, at the partner selection stage, implies the willingness to engage and to collaborate with a specific partner.

The interfirm literature points out that trust can exist at multiple levels between individuals and/or firms (e.g., Currall \& Inkpen, 2002; Velez, Sanchez, \& Alvarez-Dardet, 2008). We focus on the initial trust placed by an individual buyer manager in a potential supplier firm. More specifically, this study concentrates on the inferences that buyer managers make about a potential supplier firm using relevant information to develop perceptions of trust, upon which the decision regarding partner selection will then be based.

In the next section, we elaborate on this information-based perspective and introduce the concept of trust transferability as the theoretical background of our study.

\subsection{The notion of trust transfer and informed partner selection}

In many cases, the paucity of information about the competencies and reliability of potential partners creates a significant informational hurdle for managers that consider entering interfirm relationships (Gulati \& Gargiulo, 1999). To resolve this problem, network theorists indicate that, faced with uncertainty about a partner, actors adopt a more social orientation and resort to existing networks to discover information that lowers search costs and alleviates the risk of poor performance and potential opportunism (Baum et al., 2005; Gulati, 1998). A reasonable strategy for buyer managers, in this context, is to rely on third parties, that is, other buyer firms who have dealt with the supplier before, to guide their partner selection decisions.

Third-party information enables the formation of trust, not

\footnotetext{
2 Our conceptualization matches Sako's (1992), with competence trust as a first essential element, and goodwill trust as a second component which includes contractual trust (referring to the expectation that the other party is honest and will abide by its contractual obligations), but goes beyond that given that many relationships cannot be safeguarded by contracts alone and thus incorporates the belief that the other party will do more than formally or contractually committed to doing (generally based on expectations that the other party will behave in the interest of the relationship, without opportunism). Contractual trust is not considered as a separate dimension because, in this perspective, it is not distinct from goodwill trust (see also, Langfield-Smith, 2008).
}

based on own prior interactions and work experiences with the partner, but on the partner's history of cooperation with other firms. Arguably, third parties are influential conduits of trust because of their ability to diffuse trust-relevant information. More precisely, Uzzi (1997) indicates that third parties can function as important go-betweens and roll-over the expectations from an existing relationship to newly formed ones, furnishing a basis for trust and subsequent commitments. In this way, trust is thought to develop through a transference process (Doney \& Cannon, 1997; McEvily et al., 2003). The premise behind the concept of trust transfer is that buyer managers infer the trustworthiness of a supplier through the partnering experiences of other firms.

One situation in which this occurs is when experiences and, specifically, information about how a collaboration partner performed in previous engagements, are actively transmitted and communicated by other firms. If such third-party information is indicative of positive past performance, this increases confidence in the potential of productive future exchange. Prior research found indeed that allowing participants to know potential partners' history of cooperation with previous partners and that the history was positive increased their own willingness to initially cooperate in situations requiring trust (e.g., Bohnet \& Huck, 2004; Buskens \& Weesie, 2000). In this perspective, trust transfer is consistent with theories of performance-feedback learning (Baum et al., 2005; Li \& Rowley, 2002), where managers deal with partner uncertainty by considering the outcomes of past interactions and, logically, choosing those partners associated with favorable outcomes.

However, if trust in a partner only emerges based on information about positive past performance then, all else equal, a buyer manager's trust in the supplier should be the same in the absence of such information (regardless of whether it can be observed that other firms have done similar business with this supplier). In contrast, we draw on information-based theories of imitation to predict that the mere knowledge of third-party dealings is able to induce trust transfer.

Even in the absence of information about their outcomes, it can be reassuring to know that other firms have been involved in similar types of dealings with the partner. This is of particular relevance when new or young firms are involved, given that such firms do not have many pre-established communication channels to others, yet they may be able to observe others' ties (Stewart, 2003). Information implicit in the actions of others, although highly imperfect, can have a strong influence on managerial perceptions and beliefs (Lieberman \& Asaba, 2006). For example, buyer managers may be aware of third-party dealings with the supplier through company webpages or partner search platforms and, based on this observation, conclude that the supplier must be trustworthy. The mimetic trust hypothesis, in fact, suggests that individuals attempt to reduce uncertainty about the trustworthiness of potential trustees by imitating the choice behavior of others in a similar network position (Wittek, 2001). That is, if other trustors trust a certain trustee, their behavior can be perceived as a signal that trust can be placed safely (Barrera \& Buskens, 2007).

The preceding discussion delineates the crucial role third parties play in the development of trust and subsequent partner selection. Importantly, we put forward a distinction between two levels of third-party information, i.e., information including the positive outcomes of other firms' dealings vs. information entailing others' 
past dealings but not their outcomes. ${ }^{3}$ We see both instances as representations of trust transfer, but with variation in terms of the completeness of the information available.

In addition, we consider the interplay of these external, thirdparty, sources of information with internal knowledge available from own prior experience. The idea that learning through partner experience promotes trust is well known (e.g., Dekker, 2008; Dekker \& Van den Abbeele, 2010). Despite its importance for trust development and partner selection, however, research on thirdparty influences did not incorporate potential interactions with one's own prior experience (e.g., Barrera \& Buskens, 2007). The organizational learning literature, though, submits that such interactions are likely and, as pointed out by Schwab (2007), not accounting for them can lead to severely underspecified models. Typically, information regarding previous dealings is stored within the organization and can be accessed by its members, even if they were not personally involved in those dealings (Schilke \& Cook, 2013). Thus, even if individual managers at partner firms have not interacted directly before, the prior ties between their respective firms may lay the foundation for trust between them. This likely affects the extent to which third-party information influences trust judgments and motivates a conditional perspective on when third parties matter most.

To summarize, the theoretical model we examine appears in Fig. 1. As can be seen, trust is the keystone of the model, and is expected to mediate the relationship between third-party information and partner selection. We believe it is imperative to differentiate among competence and goodwill trust, as these concern the major uncertainties that need to be managed in interfirm relationships. That is, if third parties are theorized to be helpful because they generate trust, it is important to specify what type of trust it is and to empirically test the assumed associations. Further, recognizing the impact of learning from own prior experience, it is included to moderate the relationship between thirdparty information and trust. This set of proposed relations represents what has been termed a moderated mediation model (Preacher, Rucker, \& Hayes, 2007), and is discussed in detail in the following sections.

\subsection{The role of third-party information in forming trusting beliefs}

Considering the risk-mitigating function of trust at the relationship formation stage, we explicate how available third-party information can be interpreted to activate specific competence and goodwill trusting beliefs.

Building on prior research, we expect that knowing about other firms' dealings with the supplier, even when nothing is known about their outcomes, is able to instill competence trust. The defining features of competence trust are the various resources and capabilities of the supplier, which are needed to perform adequately and fulfill relationship objectives (Das \& Teng, 2001; Langfield-Smith, 2008). If other buyer firms have collaborated with the supplier, this signals that these firms must, at minimum, have believed that the supplier does possess the capability to accomplish given tasks in the relationship, providing a basis for competence trust. Applying the imitation logic discussed above, buyer managers would infer competence of a supplier through the partnering decisions of other buyer firms, and thus come to the conclusion that

\footnotetext{
${ }^{3}$ The outcome information we consider in this study is satisfaction with the relationship. This does not only reflect objective performance outcomes but also the relational quality underlying these outcomes and, therefore, relevant to interfirm trust development, involving both the competency and intentional aspect of trust (see also, Laan, Noorderhaven, Voordijk, \& Dewulf, 2011).
}

the partner is worthy of competence trust just because they see others do (McCutcheon \& Stuart, 2000). Such a strategy should help reduce perceived performance risk, especially when similar collaborations are concerned, such that the implied competencies are relevant to the tasks at hand. Moreover, as has been advanced in prior research (Li \& Rowley, 2002), managers evaluating potential partners will likely consider the experience that other firms have with this partner as a capability indicator. Especially when several other buyer firms have done similar business with the supplier, the supplier is assumed to have the appropriate skills and expertise, improving confidence in its ability to succeed in the collaboration. Thus, we predict a buyer manager's competence trust to be higher when the buyer manager knows other buyer firms that have done similar business with the supplier, compared to when this is not the case.

In addition, knowing that these other buyer firms were satisfied in their dealings with the supplier is likely to increase the buyer manager's competence trust in the supplier even more. In this case, buyer managers may attribute other buyer firms' satisfaction, in part, to the supplier's capabilities and expertise to perform its task effectively. Even if such capabilities cannot be directly identified, or the means-ends relationship is unclear, successful outcomes are likely to reinforce competence trusting beliefs (Li \& Rowley, 2002). In fact, firms that have been successful in previous alliances tend to build a reputation for competence (Das \& Teng, 2001). Such a favorable reputation is easily transferrable across firms (Doney \& Cannon, 1997; Ganesan, 1994), suggesting a positive association between supplier reputation and the focal buyer manager competence trust. Specifically, assuming that other firms' satisfaction with the supplier provides supplementary positive signals about the supplier's ability to perform its role competently, this should enhance competence trust more than if buyer managers initially have little or no outcome information to draw on.

This leads to the following hypothesis:

H1. The buyer manager's level of competence trust in the supplier (i) is higher when the buyer manager knows other buyer firms that have done similar business with the supplier and (ii) further increases when the buyer manager knows that this resulted in good outcomes.

Compared to competence trust, goodwill trust is argued to be relatively harder to establish and more fragile (Emsley \& Kidon, 2007). As indicated above, a straightforward way to deal with uncertainty about potential partners is to trust those who received trust choices by other firms. Because competence trust is predicated on universalistic standards (Sako, 1992), it is possible to verify competency based on information about the partner's general position in the market. Specifically, other firms choosing the supplier for similar business relationships gives the buyer manager a sense of confidence that the supplier is capable of performing its role, such that performance risk will be perceived as relatively low (Das \& Teng, 2001). The fact that other buyer firms have decided to partner with the supplier, however, does not by itself help to lower perceived relational risk. This is because relational risk is associated with the manager's concerns about the supplier's possible engagement in opportunistic behavior to exploit their vulnerabilities. Such a posture is only challengingly mitigated by other firms' dealings, especially when outcome information is lacking. Since the mere observation that others have done business with the supplier, without knowing their outcomes, does not inform about the supplier's inherent intentions to make the relationship work, we predict that it would not affect goodwill trust. Hence, unlike competence trust, which can be reasonably derived through thirdparty observation with little outcome information, we expect that trust of the goodwill sort is not as easily transferred across 


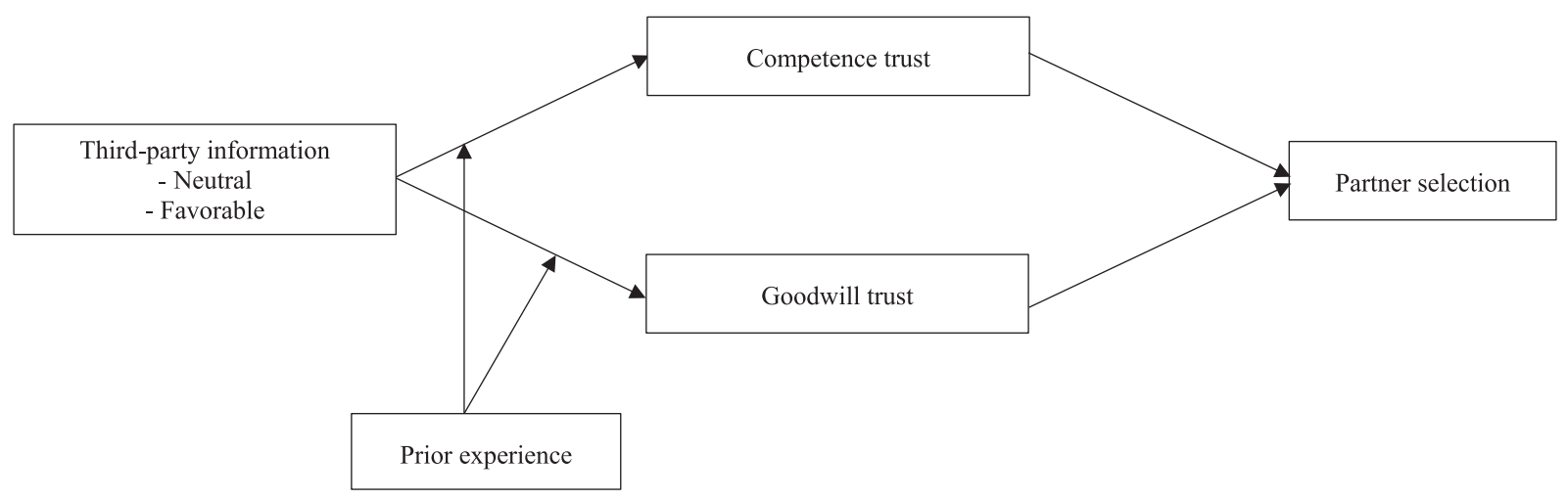

Fig. 1. Theoretical model.

relationships and thus that the mimetic trust hypothesis does not hold for goodwill trust.

Instead, verification of whether a partner is worthy of goodwill trust requires a history of demonstrated good intentions. One may argue that relational risk is very much relationship specific, and that goodwill trust can only be realized through actual interaction, not word-of-mouth (Ganesan, 1994; McCutcheon \& Stuart, 2000). At the same time, research has shown that relational behaviors of a potential supplier can be interpreted and predicted by the reputation of trustworthiness that the supplier has established in the network (e.g., Kim, 2014; Tsai \& Ghoshal, 1998). Essentially, this rests on the assumption that, if a supplier has been trustworthy for a particular set of partner firms, then they should be trustworthy for a new trustor in a structural position that is similar to those of the other trustors. Positive experiences of other buyer firms, in this sense, produce meaningful goodwill-related information, and likely influence one's own expectations about the intentions of the supplier. Specifically, if other buyers were satisfied with the relationship, this can be interpreted as the supplier dealing fairly and caring about the buyer firm's welfare. With such a reputation, the focal buyer manager may feel more assured that the supplier will cooperate in good faith, rather than behave opportunistically (Dekker, 2004; Rooks, Raub, \& Tazelaar, 2006). In line with this perspective, and other research in accounting suggesting reputation as one of the precursors of goodwill trust (e.g., Langfield-Smith, 2008; Vélez, Sánchez, \& Álvarez-Dardet, 2008), we posit that goodwill trust can be transferred, provided that sufficient information about the past is available, and that the supplier proved to be trustworthy.

This leads to the following hypothesis:

H2. The buyer manager's level of goodwill trust in the supplier (i) is unaffected when the buyer manager simply knows other buyer firms that have done similar business with the supplier but (ii) increases when the buyer manager knows other buyer firms that have done similar business with the supplier and that this resulted in good outcomes.

\subsection{The effect of trusting beliefs on partner selection}

In line with our above conceptualization of trust, and based on the theory of reasoned action (see also, Currall \& Judge, 1995; McKnight, Cummins, \& Chervany, 1998), we expect that a buyer manager's decision to engage in a collaboration with a specific supplier will be based on his/her assessment of the supplier's trustworthiness. This is consistent with observations of scholars who identify trust as one of the important criteria for partner selection (e.g., Ding et al., 2013; Shah \& Swaminathan, 2008). Moreover, in a detailed case study, Mahama and Chua (2016) report that people are more willing to collaborate with those "whom they know and trust" (p. 36). As buyers typically favor suppliers they trust in terms of competence and goodwill (Dekker et al., 2013), both dimensions of trust are relevant in this context. In fact, while firms are exposed to both performance risk and relational risk when initiating collaborations (e.g., Das \& Teng, 2001; LangfieldSmith, 2008), competence trust and goodwill trust, respectively, drive the perception that such risks are at an acceptable level. Trusting beliefs thus act as an evaluative mechanism regarding the extent to which buyer managers foresee positive outcomes to result from collaborating with the supplier. If the manager believes in the abilities and intentions of the supplier, s/he will be confident that the supplier will deliver in the future and thus will be more likely to select this supplier to collaborate with. Therefore, we predict a positive relationship between both competence trust and goodwill trust and the likelihood of the supplier to be selected.

H3. The higher the buyer manager's level of competence trust in the supplier, the higher the likelihood of the supplier to be selected.

H4. The higher the buyer manager's level of goodwill trust in the supplier, the higher the likelihood of the supplier to be selected.

\subsection{The indirect effect of third-party information on partner selection}

Given that we expect third-party information to influence trust, and trust to influence partner selection, we further propose that third-party information will have an indirect effect on partner selection via its influence on trust. That is, third-party information affects partner selection indirectly by conveying positive expectations and increasing a buyer manager's competence and/or goodwill trust in the supplier. In line with the above, simply knowing other buyer firms that have trusted the supplier is expected to promote partner selection because it increases the buyer manager's competence trust, not so much goodwill trust. If third-party information includes positive experiences, competence as well as goodwill trust may be formed, both of which in turn are expected to increase the likelihood of the supplier being selected. The corresponding hypotheses appear below, with the underlying logic that competence trust and goodwill trust result, in their own way, from third-party information and, subsequently, influence partner selection:

H5. Competence trust mediates the effects of third-party information on partner selection.

H6. Goodwill trust mediates the effects of third-party information on partner selection. 


\subsection{The moderating impact of prior experience}

When the buyer and supplier themselves have done business before, this provides the buyer manager with an initial information basis (Blumberg, 2001; Dekker \& Van den Abbeele, 2010), which may render third-party information less influential. More specifically, we posit that available information from own prior experience substitutes for third-party information in developing trust. The rationale for this substitutional effect is that, if the buyer itself had positive experiences with the supplier, the available internal information already helps to resolve many of the difficulties or uncertainties inherent in the trust problem under consideration, such that information from other firms' experiences becomes less critical. The literature offers two more detailed underlying mechanisms for this, based on information redundancy and information preferences.

First, if decision-makers are only influenced by novel or unique information, then information from multiple sources has a substitutional effect if these sources provide redundant or duplicate information (Schwab, 2007). In our context, this implies that third parties are most valuable for making trust judgments when they provide information not available elsewhere. Research in negotiations, for instance, shows that, especially in the absence of direct prior experience with a specific party, one will prepare for interactions with that party by gathering reputational information (e.g., Glick \& Croson, 2001). In contrast, when a firm is already familiar with a potential partner, they have little need of such information, as they can rely primarily on their own experience (Dekker \& Van den Abbeele, 2010). If the firm was satisfied with previous collaborations, it is plausible to assume that the supplier is sufficiently capable and not prone to opportunistic behavior (Ganesan, 1994; Rooks et al., 2006). Hence, with prior interactions and a performance history demonstrating the supplier's competence and goodwill, information about the supplier's trustworthiness via third parties will provide relatively little additional value to the buyer manager.

Second, own firm experiences are often seen as more informative than those of other firms, suggesting a preference for internal over external information. This preference for internal feedback information again suggests a substitutional effect, as available external information may be ignored (Schwab, 2007). With respect to interfirm partnering, it has been argued that decision-makers will rely on the most direct source of information and experience they have because much of the risk and uncertainty associated with partner selection is partner specific (Baum et al., 2005; Podolny, 1994). Prior studies on partner choice also provide evidence consistent with the notion that first-hand information is often preferred over second-hand information (e.g., Ding et al., 2013). According to this logic, if buyer managers already possess reliable and rich internal performance feedback, which generates confidence in the supplier's competence and goodwill (McCutcheon \& Stuart, 2000), additional available external information would not produce an effect.

Collectively, these arguments and evidence suggest that thirdparty information appeals most to those with little prior information on which to base a decision; more knowledgeable managers can rely on what they know internally (see also, Lieberman \& Asaba, 2006). Thus, while third-party information is expected to influence competence trust and goodwill trust, this influence is predicted to be weaker when the buyer and the potential supplier have had prior experience as compared to when this is not the case. Accordingly, we hypothesize that:

H7. Prior experience moderates the effects of third-party information on the buyer manager's level of competence trust, such that the effects will be weaker when the buyer has prior experience with the supplier compared to when the buyer has no prior experience with the supplier.

H8. Prior experience moderates the effects of third-party information on the buyer manager's level of goodwill trust, such that the effects will be weaker when the buyer has prior experience with the supplier compared to when the buyer has no prior experience with the supplier.

Finally, since we conceptualize a mediation effect, the moderating role of prior experience in the relationship between thirdparty information and trust implies a moderated mediation model. Specifically, H5-H6 and $\mathrm{H} 7-8$ when combined suggest that the indirect effect of third-party information on partner selection through competence trust and goodwill trust, respectively, is weaker for those with prior experience than those without prior experience. Altogether, we hypothesize the following:

H9. Prior experience moderates the indirect effects of third-party information on partner selection via competence trust, such that the indirect effects will be weaker when the buyer has prior experience with the supplier compared to when the buyer has no prior experience with the supplier.

H10. Prior experience moderates the indirect effects of thirdparty information on partner selection via goodwill trust, such that the indirect effects will be weaker when the buyer has prior experience with the supplier compared to when the buyer has no prior experience with the supplier.

\section{Method}

We use a 2 (prior experience absent vs. prior experience present) $\mathrm{x} 3$ (control group vs. neutral third-party information vs. favorable third-party information) between-subjects experimental design, in which participants were asked to indicate their trust in a potential partner, and subsequently to decide on partner selection.

\subsection{Participants and procedures}

Participants are students recruited from a postgraduate programme in management at a Western European business school. The experiment was administered during a scheduled classroom session. All participants were volunteers and, in turn for their participation, had the chance to win movie tickets. In total, 156 students completed the experiment.

The participants assumed the role of an R\&D manager in a technology firm, being responsible for finding an adequate supplier firm to collaborate with on a new product development project. This specific setting is used as it introduces interesting aspects of trust formation and subsequent partner selection. ${ }^{4}$ The situation represents a trust problem in which participants had to evaluate the trustworthiness of a potential supplier, both regarding its competence and goodwill. It was explicitly emphasized that the success of the collaboration would depend on their supplier

\footnotetext{
${ }^{4}$ In new product development relationships, there is a high need for the firm to establish trust in the partner company. In fact, trust between partners is an essential element for successful collaboration in new product development; much more than in other buyer-supplier relationships that are less uncertain and less risky (see also, Bstieler, 2006; Jørgensen \& Messner, 2010).
} 
selection. $^{5}$

The experimental procedure was as follows. After explaining the instructions, participants were asked to read the scenario. The basic scenario was described on the first page and all participants received the same information to this point. Besides their role description, participants were told that the new product development is of crucial strategic importance to the firm and involves a large amount of money. This is included to reflect situational importance and to induce individuals to more carefully evaluate the situation before making decisions. Furthermore, participants were informed that the outcomes of the project will only become clear after the project has been initiated, and especially will hinge upon the working relationship with the supplier. The reason for this is that actively looking for information about the potential partner is more likely to take place in relatively uncertain and risky situations. ${ }^{6}$ After pointing this out, participants were instructed to the second page, presenting a more detailed description of a potential supplier with whom their firm can do business, including the experimental manipulations. Participants were randomly assigned to one of the six experimental conditions. In the next step, participants were asked to indicate their trust in the supplier described to them, and subsequently the likelihood they would select this particular supplier to collaborate with. Finally, participants had to respond to two manipulation check questions, and were asked to fill in some demographic questions, as well as questions regarding their motivation to perform the experiment and their understanding of the experimental task.

\subsection{Manipulations}

The two independent variables manipulated in our experiment are information from own firm experience and from third parties. First, information from own prior experience was manipulated by telling the participants either that their firm has never done business before with the supplier (prior experience absent condition) or that their firm has done business with the supplier before and was satisfied with this (prior experience present condition). Second, third-party information is manipulated by either giving no information about other buyer firms' previous experiences with the supplier (control group), by indicating that they know other buyer firms that have done similar business with the supplier (neutral third-party information condition) or by indicating that they know other buyer firms that have done similar business with the supplier and were satisfied (favorable third-party information condition). We use these three levels in order to study the difference between no information, neutral information, and favorable information related to others' experiences with the partner. After all, trust transfer might occur without knowing the outcomes obtained by others, or could be based on information that includes the outcomes of a given collaboration.

\subsection{Measures}

Regarding the dependent variables, the participants were asked to answer a series of questions reflecting their trust in the supplier,

\footnotetext{
${ }^{5}$ In order to gauge the perceived importance of trust under the specific scenario, we asked the participants in our post-experimental questionnaire to indicate how critical trust was for partner selection (cf. Shah \& Swaminathan, 2008). In line with the proposed logic, participants reported high criticality ratings for both the partner's competence and goodwill.

${ }^{6}$ In this regard, the trust literature also suggests that trusting parties must be vulnerable, to some extent, for trust to become operational. In other words, decision outcomes must be uncertain and important to the trustor; otherwise trust would not be needed (see also, Dekker et al., 2013; Vélez et al., 2008).
}

derived from existing scales to measure trust and adapted to the interfirm setting (e.g., McKnight, Choudhury, \& Kacmar, 2002; Nicolaou \& McKnight, 2006; Nicolaou et al., 2011; Anderson et al., 2017). The first six items in the scale capture benevolence and integrity which reflect the individual's belief in the supplier's goodwill, whereas the last three items capture the individual's belief in the supplier's competence. Furthermore, participants were asked to make decisions on partner selection. Specifically, participants needed to indicate how likely it would be that they would select the supplier described in the experiment, if they had to make a choice. ${ }^{7}$ In addition, we measured participants' disposition to trust, using a three-item scale found in prior research, as this may also influence trusting beliefs and behaviors towards the supplier (e.g., McKnight et al., 2002; Nicolaou \& McKnight, 2006). ${ }^{8}$ Disposition to trust represents an individual's general tendency to trust others. It has been emphasized in the trust literature that an understanding of trust necessitates consideration of this personality characteristic (e.g., Mayer et al., 1995; McKnight et al., 2002) and is, therefore, incorporated as a covariate in our model. ${ }^{9}$ Scale items are presented in Supplement I of Appendix A. All questions were to be answered on a seven-point Likert-type scale.

\section{Results}

We test our hypotheses by conducting the following analyses. First, analyses of covariance (ANCOVA) are used to test the main effects of third-party information on competence trust and goodwill trust, controlling for the effects of trust disposition $(\mathrm{H} 1-\mathrm{H} 2)$. Second, we perform a path analysis that allows us to simultaneously test all relationships proposed in our model, including both direct and indirect linkages, and conditional effects ( $\mathrm{H} 3-\mathrm{H} 10)$. Prior to our main analyses, we performed manipulation checks on the experimental conditions, and validated the measurement scales.

\subsection{Manipulation checks}

Participants had to respond to two manipulation check questions. The first question asked participants whether their firm has done business before with the supplier: "yes" or "no". The second question asked participants whether they knew any other firms that have done similar business with the supplier: "yes" or "no". Of the 156 participants enrolled in the experimental sessions, 38 failed at least one of the manipulation check questions. These participants are excluded from our subsequent analyses, leaving us with 118

\footnotetext{
7 Participants were also asked to provide an assessment of their willingness to engage in a collaboration with the supplier described in the experiment. The results using this measure are qualitatively similar to the results using the supplier selection measure.

${ }^{8}$ We also measured other personal characteristics such as uncertainty avoidance, preference for risk-taking behavior, and susceptibility for third-party influences, but these were not found to be significantly related to our variables of interest and the inclusion or exclusion of these covariates did not affect the significance of the model relationships.

9 Significant differences exist in participants' disposition to trust across some of the experimental conditions, but given that there is no clear pattern observable and our model in itself does not explain variation in trust disposition (that is, neither third-party information nor prior experience explains observed variation in this variable), we attribute this to mere chance rather than a systematic treatment effect, consistent with the idea that trust disposition reflects a stable within-person
} factor. 
usable observations in total, and approximately 20 per cell. $^{10}$

To further assess the effectiveness of our manipulations, participants were also asked to indicate how they would characterize their firm's satisfaction about its prior dealings with the supplier, in case their firm had done business with the supplier before. This question was answered by the participants in the prior experience present condition, and resulted in a mean score $(M=6.00$; $\mathrm{SD}=0.53)$ that is significantly higher than the midpoint of the scale. In a similar vein, in case they knew other firms that have done similar business with the supplier, participants were asked to indicate how they would characterize these other firms' satisfaction about their dealings with the supplier. Most of the participants in the neutral third-party information condition correctly indicated "do not know", as this was not explicitly mentioned. Of the participants in the favorable third-party information condition, none indicated "do not know", yielding a mean score $(M=6.05$; $\mathrm{SD}=0.93$ ) that is significantly higher than the midpoint of the scale. $^{11}$

Of the final sample of participants, $56 \%$ were male, the average age was 24 years, and the majority had working experience of more than 12 months. The demographic data were tested for differences across experimental conditions to determine whether randomization was successful. As desired, no significant differences were found (all $p>0.10$ ). The mean scores of motivation to perform the experiment $(\mathrm{M}=4.40 ; \mathrm{SD}=1.05)$ and clarity of the experimental task $(M=4.40 ; S D=1.26)$ were significantly larger than the midpoint of the scale, indicating that the participants were well motivated and understood the task. We did not find any significant differences across the experimental conditions on these variables either (all p > 0.10).

\subsection{Measurement validation}

Given that we adapted the measures of trust from prior studies, we performed an exploratory factor analysis (EFA) on the set of nine questions to assess the validity of the construct. The results reveal two distinct factors (eigenvalues larger than 1; accounting for $57.34 \%$ of the variance). The first six items load on one factor, representing goodwill trust. The last three items load on the second factor, representing competence trust. We further evaluated the trust construct by running a confirmatory factor analysis (CFA). The model distinguishing between goodwill trust and competence trust demonstrates a good fit $\left(\chi^{2} / \mathrm{df}=1.08 ; \mathrm{GFI}=0.95 ; \quad \mathrm{CFI}=0.99\right.$; RMSEA $=0.03)$. All items load significantly on their respective factors, indicating convergent validity of the measures. To assess discriminant validity, we computed the average variance extracted, and found that these are greater than the shared variance between

\footnotetext{
${ }^{10}$ As a way to explore the reason for participants failing manipulation checks, we looked at the motivation to perform the experiment of those who failed the manipulation checks. The test revealed a mean score insignificantly different from the midpoint of the scale $(M=4.08 ; S D=1.38)$. This indicates that these participants were not well motivated and might have caused them to pay insufficient attention to the details in the experiment, providing an explanation for their incorrect answers. As a robustness check, we reran the analyses using the full sample and found that the results remain qualitatively the same, although the statistical significance of the effects of third-party information on competence trust becomes slightly weaker.

11 Some of the participants in the neutral third-party information condition indicated a satisfaction level ranging from 4 to 7 , with the mean score $(M=5.36$; $\mathrm{SD}=0.56$ ) significantly higher than the midpoint of the scale. Thus, an intriguing result of the experimental manipulation is that, if they are told that others have done business with the supplier, some participants infer that it must have been good, even when the outcomes are not explicitly mentioned. However, in the favorable third-party information condition, participants scored the satisfaction levels significantly higher than in the neutral condition $(t=2.74 ; p<0.01)$. Based on this we conclude that the manipulations have worked.
}

the factors. Moreover, constrained analyses show a significant difference in chi-square values between the constrained and unconstrained model, confirming discriminant validity. The Cronbach alpha of 0.79 for competence trust and 0.78 for goodwill trust reflects high construct reliability. In testing the hypotheses, we differentiate between competence trust and goodwill trust, and derive these two variables by calculating individual scores as means of the combined scale items. Table 1 reports the descriptive statistics for both competence trust and goodwill trust by experimental condition.

For trust disposition, all items significantly load on one factor. Cronbach alpha equals 0.73 . From this we conclude that the measure is valid and reliable.

\subsection{ANCOVA: testing $\mathrm{H} 1-\mathrm{H} 2$}

The first set of hypotheses relates to the effects of third-party information on the buyer manager's trust in a potential supplier firm, holding the effect of own firm experience constant. Table 2 and Table 3 present the results for competence trust and goodwill trust, respectively. Panel A provides the means and standard errors by condition. Panel B provides the ANCOVA results. As indicated above, we include trust disposition as covariate to control for the variation in participants' inherent propensity to trust. ${ }^{12}$

To investigate differences in trust formation between the thirdparty information treatments, and test for $\mathrm{H} 1$ and $\mathrm{H} 2$, we use planned comparisons.

Specifically, H1 predicts (i) an increase in competence trust when the buyer manager knows other buyer firms that have done similar business with the supplier and (ii) an additional increase when it is known that this resulted in good outcomes. The results in Table 2 Panel $\mathrm{C}$ indicate that, compared to the control group, competence trust is significantly higher in the neutral third-party information condition (mean difference $=0.26, \mathrm{p}=0.06$ ). ${ }^{13}$ This pattern of results is illustrated in Fig. 2. As the neutral third-party information condition results in higher competence trust than in the control condition, we find support for trust transfer, even in the absence of relevant outcome information. However, no significant difference is observed when we compare the neutral and favorable third-party information conditions (mean difference $=0.12$, $\mathrm{p}=0.24$ ). The rational or adaptive response to outcome feedback would be to incorporate the implications of the additional information, leading to a further increase in competence trust. Yet, even though the effect of additional outcome information is in the predicted direction, it does not turn out to be significant. ${ }^{14}$ Thus, the results support part (i) of $\mathrm{H} 1$ but not part (ii).

Further, H2 predicts (i) no effect on goodwill trust when the buyer manager simply knows other buyer firms that have done similar business with the supplier but (ii) an increase when it is known that this resulted in good outcomes. Consistent with these two predictions, results in Table 3 Panel $\mathrm{C}$ indicate that goodwill trust does not significantly differ between the control group and

\footnotetext{
12 The results without trust disposition as covariate are reported in the online supplement (see Appendix A, Supplement II). It must be noted that, while the inclusion of the covariate does not alter the model estimates for competence trust, the effects of third-party information on goodwill trust are reliant on the presence of the covariate. Our findings should be interpreted in light of this.

${ }^{13} \mathrm{p}$-values are reported on a one-tailed basis, given the directional predictions of the effects.

14 As implied by the above findings, competence trust is not significantly higher in the favorable third-party information condition as compared to the neutral thirdparty information condition, but favorable third-party information does produce a significant increase in competence trust as compared to the control condition (mean difference $=0.37, \mathrm{p}=0.01$ ).
} 
Table 1

Descriptive statistics.

\begin{tabular}{|c|c|c|c|c|}
\hline \multicolumn{5}{|c|}{ Means and Standard Deviations for Competence trust } \\
\hline \multirow[t]{2}{*}{ Prior experience } & \multicolumn{3}{|c|}{ Third-party information } & \multirow[b]{2}{*}{ Row total } \\
\hline & Control group & Neutral & Favorable & \\
\hline Absent & $\begin{array}{l}4.76 \\
(0.61) \\
n=21\end{array}$ & $\begin{array}{l}5.09 \\
(0.67) \\
n=19\end{array}$ & $\begin{array}{l}5.11 \\
(0.75) \\
n=19\end{array}$ & $\begin{array}{l}4.98 \\
(0.68) \\
n=59\end{array}$ \\
\hline Present & $\begin{array}{l}5.33 \\
(0.75) \\
n=21\end{array}$ & $\begin{array}{l}5.53 \\
(0.70) \\
n=19\end{array}$ & $\begin{array}{l}5.68 \\
(0.86) \\
n=19\end{array}$ & $\begin{array}{l}5.50 \\
(0.77) \\
n=59\end{array}$ \\
\hline Column total & $\begin{array}{l}5.05 \\
(0.73) \\
n=42\end{array}$ & $\begin{array}{l}5.31 \\
(0.71) \\
\mathrm{n}=38\end{array}$ & $\begin{array}{l}5.39 \\
(0.84) \\
\mathrm{n}=38\end{array}$ & \\
\hline \multicolumn{5}{|c|}{ Means and Standard Deviations for Goodwill trust } \\
\hline \multirow[t]{2}{*}{ Prior experience } & \multicolumn{3}{|c|}{ Third-party information } & \\
\hline & Control group & Neutral & Favorable & Row total \\
\hline Absent & $\begin{array}{l}4.60 \\
(0.68) \\
n=21\end{array}$ & $\begin{array}{l}4.62 \\
(0.56) \\
n=19\end{array}$ & $\begin{array}{l}4.63 \\
(0.84) \\
\mathrm{n}=19\end{array}$ & $\begin{array}{l}4.62 \\
(0.59) \\
n=59\end{array}$ \\
\hline Present & $\begin{array}{l}5.03 \\
(0.43) \\
n=21\end{array}$ & $\begin{array}{l}5.04 \\
(0.76) \\
\mathrm{n}=19\end{array}$ & $\begin{array}{l}5.26 \\
(0.62) \\
n=19\end{array}$ & $\begin{array}{l}5.11 \\
(0.61) \\
n=59\end{array}$ \\
\hline Column total & $\begin{array}{l}4.81 \\
(0.61) \\
n=42\end{array}$ & $\begin{array}{l}4.83 \\
(0.69) \\
\mathrm{n}=38\end{array}$ & $\begin{array}{l}4.95 \\
(0.79) \\
n=38\end{array}$ & \\
\hline
\end{tabular}

Note: Means are reported with Standard Deviations in parentheses.

Table 2

ANCOVA on Competence trust.

\begin{tabular}{|c|c|c|c|c|c|c|}
\hline \multicolumn{7}{|c|}{ PANEL A: Adjusted Means and Standard Errors ${ }^{\mathrm{a}}$} \\
\hline \multirow[t]{2}{*}{ Prior experience } & \multicolumn{4}{|c|}{ Third-party information } & \multirow{2}{*}{\multicolumn{2}{|c|}{ Row total }} \\
\hline & Control group & \multicolumn{2}{|l|}{ Neutral } & Favorable & & \\
\hline Absent & $\begin{array}{l}4.74 \\
(0.16) \\
n=21\end{array}$ & \multicolumn{2}{|l|}{$\begin{array}{l}5.09 \\
(0.17) \\
n=19\end{array}$} & \multicolumn{2}{|l|}{$\begin{array}{l}5.14 \\
(0.16) \\
n=19\end{array}$} & $\begin{array}{l}4.99 \\
(0.09) \\
n=59\end{array}$ \\
\hline Present & $\begin{array}{l}5.34 \\
(0.16) \\
n=21\end{array}$ & $\begin{array}{l}5.50 \\
(0.17) \\
n=19\end{array}$ & & $\begin{array}{l}5.68 \\
(0.17) \\
n=19\end{array}$ & & $\begin{array}{l}5.51 \\
(0.09) \\
n=59\end{array}$ \\
\hline Column total & $\begin{array}{l}5.04 \\
(0.11) \\
\mathrm{n}=42\end{array}$ & $\begin{array}{l}5.30 \\
(0.12) \\
n=38\end{array}$ & & $\begin{array}{l}5.41 \\
(0.12) \\
n=38\end{array}$ & & \\
\hline \multicolumn{7}{|l|}{ PANEL B: Test of Between-Subjects Effects ${ }^{\mathrm{b}}$} \\
\hline Source & Sum of Squares & df & Mean Square & $\mathrm{F}$ & \multicolumn{2}{|c|}{ p-value (two-tailed) } \\
\hline $\begin{array}{l}\text { Trust disposition } \\
\text { Third-party information } \\
\text { Prior experience } \\
\text { Third-party information* Prior experience } \\
\text { error }\end{array}$ & $\begin{array}{l}1.00 \\
2.92 \\
7.77 \\
0.18 \\
57.63\end{array}$ & $\begin{array}{l}1 \\
2 \\
1 \\
2 \\
111\end{array}$ & $\begin{array}{l}1.00 \\
1.46 \\
7.77 \\
0.09 \\
0.52\end{array}$ & $\begin{array}{l}1.92 \\
2.82 \\
14.97 \\
0.17\end{array}$ & $\begin{array}{l}0.17 \\
0.06 \\
<0.01 \\
0.84\end{array}$ & \\
\hline \multicolumn{7}{|l|}{ PANEL C: Planned Comparisons } \\
\hline \multicolumn{3}{|c|}{$\begin{array}{l}\text { Neutral third-party information vs. Control group (H1(i)) } \\
\text { Favorable third-party information vs. Neutral third-party information (H1(ii)) } \\
\text { Favorable third-party information vs. Control group }\end{array}$} & $\begin{array}{l}0.26 \\
0.12 \\
0.37\end{array}$ & & $\begin{array}{l}0.06 \\
0.24 \\
0.01\end{array}$ & \\
\hline
\end{tabular}

${ }^{a}$ Means are adjusted for the effect of the covariate, evaluated at mean $=4.69$

b Model $\mathrm{F}=3.88$ (significance $=0.002$ ); Adjusted R-squared $=0.13$.

the neutral third-party information condition (mean

\footnotetext{
${ }^{15}$ Comparing the neutral and favorable third-party information conditions, it appears that goodwill trust is also significantly higher in the favorable third-party information condition than in the neutral third-party information condition (mean difference $=0.20, \mathrm{p}=0.08$ ).
}

difference $=0.01, p=0.48$ ), yet is significantly higher in the favorable third-party information condition than in the control group (mean difference $=0.21, \mathrm{p}=0.07){ }^{15}$ This pattern of results is illustrated in Fig. 3. Since information about other firms' experiences without knowing the outcomes, as far as our data can tell, does not lead to higher goodwill trust than in the control condition, 
Table 3

ANCOVA on Goodwill trust.

\begin{tabular}{|c|c|c|c|c|c|c|}
\hline \multicolumn{7}{|l|}{ PANEL A: Adjusted Means and Standard Errors ${ }^{a}$} \\
\hline \multirow[t]{2}{*}{ Prior experience } & \multicolumn{4}{|c|}{ Third-party information } & \multirow{2}{*}{\multicolumn{2}{|c|}{ Row total }} \\
\hline & Control group & \multicolumn{2}{|l|}{ Neutral } & Favorable & & \\
\hline Absent & $\begin{array}{l}4.54 \\
(0.14) \\
\mathrm{n}=21\end{array}$ & \multicolumn{2}{|l|}{$\begin{array}{l}4.63 \\
(0.14) \\
n=19\end{array}$} & \multicolumn{2}{|l|}{$\begin{array}{l}4.73 \\
(0.14) \\
n=19\end{array}$} & $\begin{array}{l}4.64 \\
(0.08) \\
n=59\end{array}$ \\
\hline Present & $\begin{array}{l}5.04 \\
(0.13) \\
n=21\end{array}$ & $\begin{array}{l}4.97 \\
(0.14)\end{array}$ & & 5.26 & & $\begin{array}{l}5.09 \\
(0.08) \\
n=59\end{array}$ \\
\hline Column total & $\begin{array}{l}4.79 \\
(0.10) \\
n=42\end{array}$ & $\begin{array}{l}4.80 \\
(0.10) \\
\mathrm{n}=38\end{array}$ & & $\begin{array}{l}5.00 \\
(0.10) \\
\mathrm{n}=38\end{array}$ & & \\
\hline \multicolumn{7}{|l|}{ PANEL B: Test of Between-Subjects Effects ${ }^{\mathrm{b}}$} \\
\hline Source & Sum of Squares & df & Mean Square & $\mathrm{F}$ & p-value & two-tailed) \\
\hline $\begin{array}{l}\text { Trust disposition } \\
\text { Third-party information } \\
\text { Prior experience } \\
\text { Third-party information*Prior experience } \\
\text { error }\end{array}$ & $\begin{array}{l}6.91 \\
1.03 \\
6.09 \\
0.21 \\
42.01\end{array}$ & $\begin{array}{l}1 \\
2 \\
1 \\
2 \\
111\end{array}$ & $\begin{array}{l}6.91 \\
0.52 \\
6.09 \\
0.11 \\
0.38\end{array}$ & $\begin{array}{l}18.26 \\
1.36 \\
16.08 \\
0.28\end{array}$ & $\begin{array}{l}<0.01 \\
0.26 \\
<0.01 \\
0.76\end{array}$ & \\
\hline \multicolumn{7}{|l|}{ PANEL C: Planned Comparisons } \\
\hline & & & \multicolumn{2}{|l|}{ Mean Difference } & \multicolumn{2}{|c|}{ p-value (one-tailed) } \\
\hline $\begin{array}{l}\text { Neutral third-party information vs. Contro } \\
\text { Favorable third-party information vs. Neut } \\
\text { Favorable third-party information vs. Cont }\end{array}$ & $\begin{array}{l}\text { group }(\mathbf{H} 2(\mathbf{i})) \\
\text { al third-party information } \\
\text { ol group }(\mathbf{H} 2(\mathbf{i i}))\end{array}$ & & $\begin{array}{l}0.01 \\
0.20 \\
0.21\end{array}$ & & $\begin{array}{l}0.48 \\
0.08 \\
0.07\end{array}$ & \\
\hline
\end{tabular}

Favorable third-party information vs. Control group (H

${ }^{\text {a }}$ Means are adjusted for the effect of the covariate, evaluated at mean $=4.69$.

b Model $\mathrm{F}=6.49$ ( significance $=0.000)$; Adjusted R-squared $=0.22$.

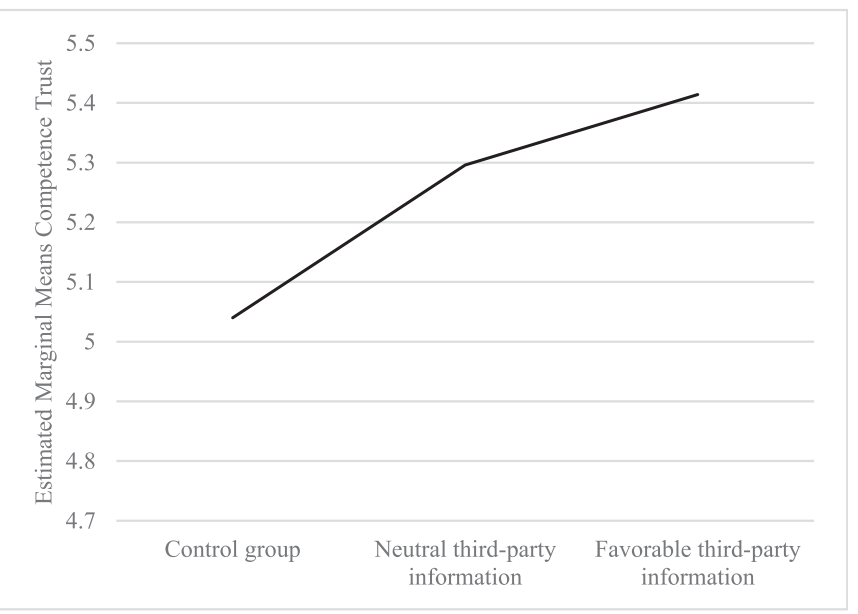

Fig. 2. Third-party information effects on Competence trust. The figure displays estimated marginal means of competence trust for the three third-party information experimental conditions (control group, neutral third-party information, favorable third-party information). The estimates include participants' trust disposition as a covariate (evaluated at mean $=4.69$ ).

but increases when additional outcome information is provided, this provides support for $\mathrm{H} 2$ (i) and (ii).

In sum, the results show that knowledge of other firms' dealings with the supplier, even without any outcome information, increases participants' level of competence trust in the supplier. However, for goodwill trust, we do not find this to be a sufficient condition, presumably because neutral third-party information lacks the content to reduce uncertainty about the supplier's good intentions. The participants' goodwill trust does increase when it is known that other firms had good outcomes, such that it provides

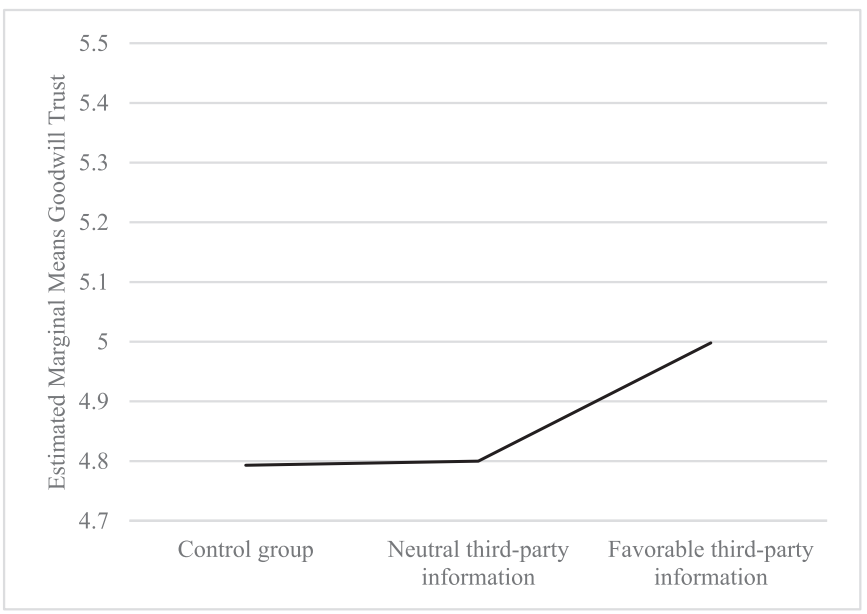

Fig. 3. Third-party information effects on Goodwill trust. The figure displays estimated marginal means of goodwill trust for the three third-party information experimental conditions (control group, neutral third-party information, favorable thirdparty information). The estimates include participants' trust disposition as a covariate (evaluated at mean $=4.69$ ).

confidence in the supplier's cooperative intent. These findings thus point to the relative ease of transferring competence trust, as compared to goodwill trust. ${ }^{16}$

\subsection{Path analysis: testing $\mathrm{H} 3-\mathrm{H} 10$}

To analyze the subsequent effects on partner selection, we

16 Additional analyses on the differential effects for competence trust and good-
will trust are provided in the online supplement (see Appendix A, Supplement III). 
perform a path analysis that estimates the links among third-partyinformation, competence trust and goodwill trust, and the likelihood to select, while controlling for trust disposition. To remain consistent with the analysis of moderated mediation, the effect of prior experience is also included. The path coefficients are presented in Table 4 and Fig. 4.

Since we have three condition treatments for third-party information, and the three levels of manipulation can be rank ordered with respect to the completeness of the information available, we in one group relative to the group one step sequentially lower in the ordered system. In our case, this allows us to compare the neutral third-party information condition relative to the control group, and the favorable third-party information condition relative to the neutral third-party information condition. With indicator coding, the control group functions as the reference group, allowing us to investigate the effects of the neutral and favorable third-party information experimental conditions, relative to the control group.

For completeness, we first assess the link between third-party

Table 4

Path coefficients.

\begin{tabular}{|c|c|c|c|c|}
\hline & Estimate & Standard Error & t-statistic & p-value (one-tailed) \\
\hline \multicolumn{5}{|l|}{ PANEL A: Sequential coding ${ }^{a}$} \\
\hline \multicolumn{5}{|l|}{ Paths to Competence trust $\left(R^{2}=0.17\right)$} \\
\hline Neutral third-party information $\rightarrow$ Competence trust $(\mathbf{H 1}(\mathbf{i}))$ & 0.26 & 0.16 & 1.59 & 0.06 \\
\hline Favorable third-party information $\rightarrow$ Competence trust (H1(ii)) & 0.12 & 0.17 & 0.71 & 0.24 \\
\hline Prior experience $\rightarrow$ Competence trust & 0.60 & 0.22 & 2.67 & $<0.01$ \\
\hline Neutral third-party information*Prior experience $\rightarrow$ Competence trust $(\mathbf{H 7})$ & -0.19 & 0.32 & -0.57 & 0.28 \\
\hline Favorable third-party information*Prior experience $\rightarrow$ Competence trust $(\mathbf{H 7})$ & 0.13 & 0.33 & 0.40 & 0.35 \\
\hline Trust disposition $\rightarrow$ Competence trust & 0.09 & 0.07 & 1.39 & 0.08 \\
\hline \multicolumn{5}{|l|}{ Paths to Goodwill trust $\left(R^{2}=0.26\right)$} \\
\hline Neutral third-party information $\rightarrow$ Goodwill trust & 0.01 & 0.14 & 0.05 & 0.48 \\
\hline Favorable third-party information $\rightarrow$ Goodwill trust & 0.20 & 0.14 & 1.39 & 0.08 \\
\hline Prior experience $\rightarrow$ Goodwill trust & 0.50 & 0.19 & 2.63 & $<0.01$ \\
\hline Neutral third-party information*Prior experience $\rightarrow$ Goodwill trust & -0.16 & 0.28 & -0.59 & 0.28 \\
\hline Favorable third-party information*Prior experience $\rightarrow$ Goodwill trust & 0.19 & 0.28 & 0.69 & 0.25 \\
\hline Trust disposition $\rightarrow$ Goodwill trust & 0.24 & 0.06 & 4.27 & $<0.01$ \\
\hline \multicolumn{5}{|l|}{ Paths to Partner selection $\left(R^{2}=0.30\right)$} \\
\hline Competence trust $\rightarrow$ Partner selection (H3) & 0.28 & 0.12 & 2.26 & 0.01 \\
\hline Goodwill trust $\rightarrow$ Partner selection (H4) & 0.41 & 0.14 & 2.85 & $<0.01$ \\
\hline Neutral third-party information $\rightarrow$ Partner selection & -0.06 & 0.19 & -0.32 & 0.37 \\
\hline Favorable third-party information $\rightarrow$ Partner selection & 0.19 & 0.20 & 0.95 & 0.17 \\
\hline Prior experience $\rightarrow$ Partner selection & 0.38 & 0.17 & 2.20 & 0.02 \\
\hline Trust disposition $\rightarrow$ Partner selection & -0.00 & 0.08 & -0.04 & 0.48 \\
\hline \multicolumn{5}{|l|}{ PANEL B: Indicator coding ${ }^{\mathrm{b}}$} \\
\hline \multicolumn{5}{|l|}{ Paths to Competence trust $\left(R^{2}=0.17\right)$} \\
\hline Neutral third-party information $\rightarrow$ Competence trust & 0.26 & 0.16 & 1.59 & 0.06 \\
\hline Favorable third-party information $\rightarrow$ Competence trust & 0.37 & 0.16 & 2.30 & 0.01 \\
\hline Prior experience $\rightarrow$ Competence trust & 0.60 & 0.22 & 2.67 & $<0.01$ \\
\hline Neutral third-party information*Prior experience $\rightarrow$ Competence trust & -0.19 & 0.32 & -0.57 & 0.28 \\
\hline Favorable third-party information*Prior experience $\rightarrow$ Competence trust & -0.06 & 0.33 & -0.17 & 0.43 \\
\hline Trust disposition $\rightarrow$ Competence trust & 0.09 & 0.07 & 1.39 & 0.08 \\
\hline \multicolumn{5}{|l|}{ Paths to Goodwill trust $\left(R^{2}=0.26\right)$} \\
\hline Neutral third-party information $\rightarrow$ Goodwill trust $(\mathbf{H 2}(\mathbf{i}))$ & 0.01 & 0.14 & 0.05 & 0.48 \\
\hline Favorable third-party information $\rightarrow$ Goodwill trust (H2(ii)) & 0.21 & 0.14 & 1.48 & 0.07 \\
\hline Prior experience $\rightarrow$ Goodwill trust & 0.50 & 0.19 & 2.63 & $<0.01$ \\
\hline Neutral third-party information*Prior experience $\rightarrow$ Goodwill trust (H8) & -0.16 & 0.28 & -0.59 & 0.28 \\
\hline Favorable third-party information*Prior experience $\rightarrow$ Goodwill trust (H8) & 0.03 & 0.28 & 0.10 & 0.46 \\
\hline Trust disposition $\rightarrow$ Goodwill trust & 0.24 & 0.06 & 4.27 & $<0.01$ \\
\hline \multicolumn{5}{|l|}{ Paths to Partner selection $\left(R^{2}=0.30\right)$} \\
\hline Competence trust $\rightarrow$ Partner selection $(\mathbf{H} 3)$ & 0.28 & 0.12 & 2.26 & 0.01 \\
\hline Goodwill trust $\rightarrow$ Partner selection (H4) & 0.41 & 0.14 & 2.85 & $<0.01$ \\
\hline Neutral third-party information $\rightarrow$ Partner selection & -0.06 & 0.19 & -0.32 & 0.37 \\
\hline Favorable third-party information $\rightarrow$ Partner selection & 0.13 & 0.20 & 0.64 & 0.26 \\
\hline Prior experience $\rightarrow$ Partner selection & 0.38 & 0.17 & 2.20 & 0.02 \\
\hline Trust disposition $\rightarrow$ Partner selection & -0.00 & 0.08 & -0.04 & 0.48 \\
\hline
\end{tabular}

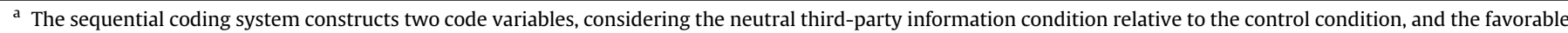

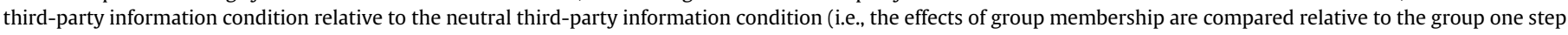
sequentially lower in the ordered system).

b The indicator coding system constructs two code variables, comparing the experimental conditions of neutral and favorable third-party information, respectively, with the control condition (i.e., the control group functions as the reference group).

use both a sequential and indicator coding system to fully represent the relative effects (Hayes \& Preacher, 2014). With sequential codes, the relative effects can be interpreted as the effects of membership information and trusting beliefs, in line with the results discussed above. The path coefficients to competence trust in Panel A of Table 4 and Fig. 4 quantify the mean differences in competence 
PANEL A: Sequential Coding

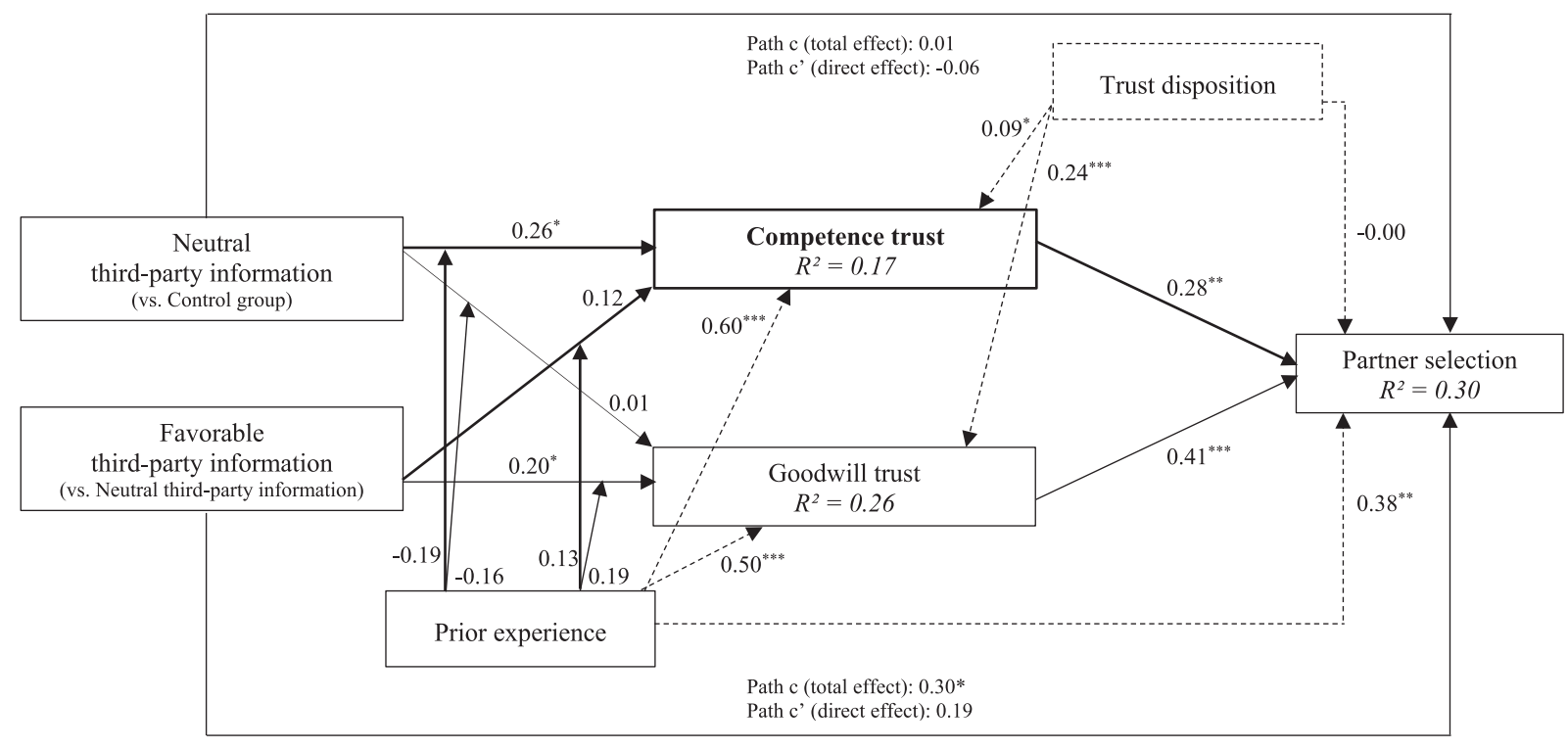

PANEL B: Indicator Coding

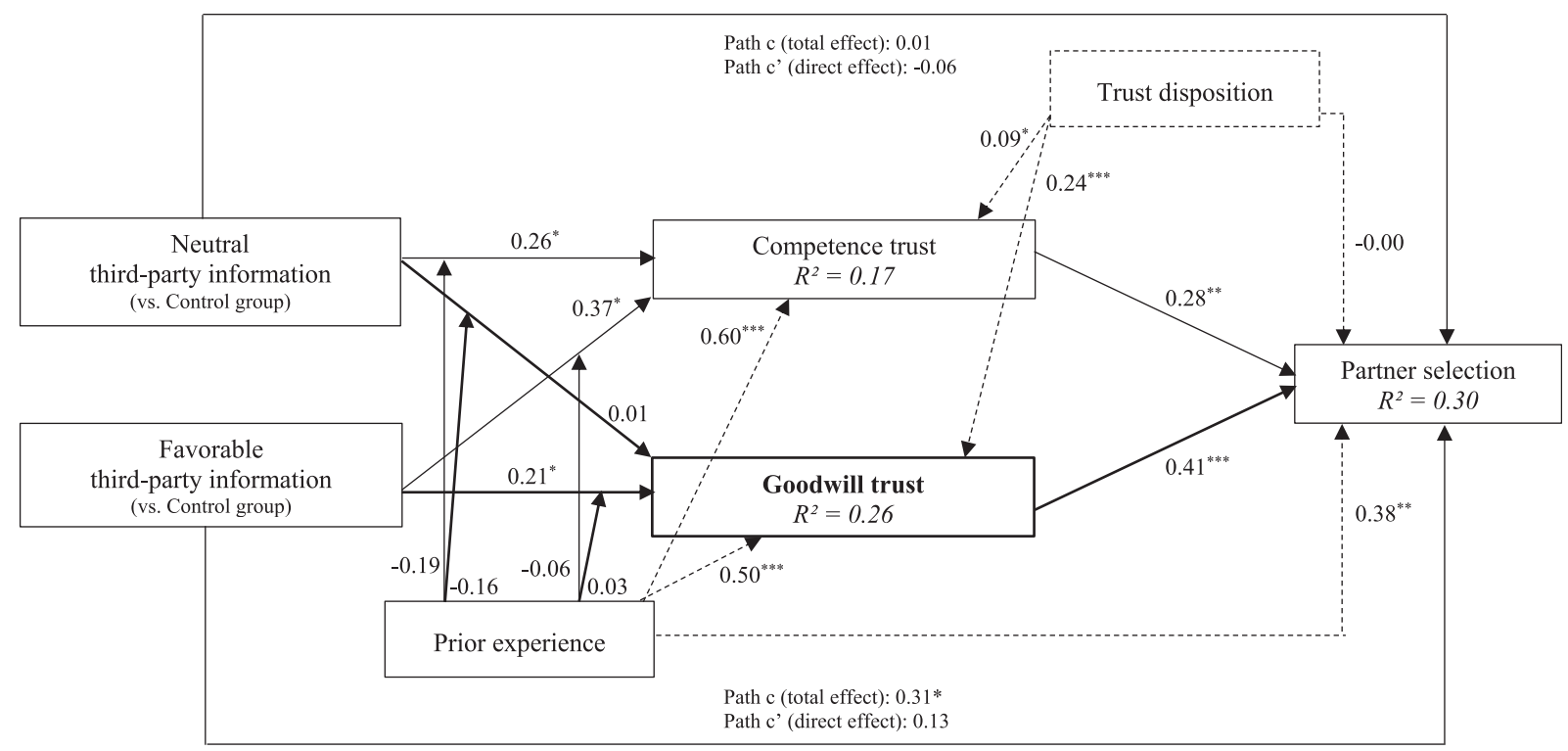

Fig. 4. Empirical Results. The figure presents the moderated mediation model, controlling for trust disposition.

PANEL A: Sequential Coding

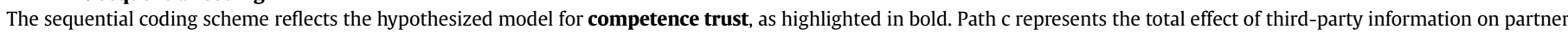

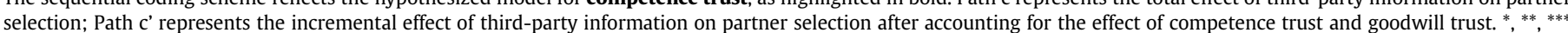
indicate significance at the 10 percent, 5 percent, and 1 percent levels, respectively (one-tailed).

PANEL B: Indicator Coding

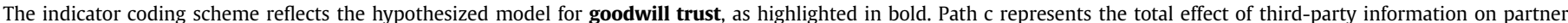

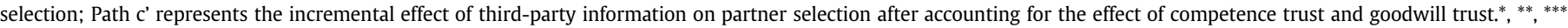
indicate significance at the 10 percent, 5 percent, and 1 percent levels, respectively (one-tailed).

trust between the neutral third-party information and control condition, and between the favorable and neutral third-party information condition, confirming our earlier findings with respect to H1. The results show a significant path from neutral third-party information to competence trust $(\beta=0.26, p=0.06)$, yet favorable third-party information does not produce an additional significant increase $(\beta=0.12, p=0.24)$. The path coefficients to goodwill trust in Panel B of Table 4 and Fig. 4 are particularly instructive with respect to the pattern predicted in H2. Again, we find that, compared to the control group, neutral third-party information shows no significant effect on goodwill trust $(\beta=0.01$, $\mathrm{p}=0.48)$, while favorable third-party information does $(\beta=0.21$, $\mathrm{p}=0.07)$.

Regarding the second link in our model, we predicted that the buyer manager's level of competence trust and goodwill trust will be positively associated with the likelihood of the supplier being selected. As expected, we find that both competence trust $(\beta=0.28$, $\mathrm{p}=0.01)$ and goodwill trust $(\beta=0.41, \mathrm{p}<0.01)$ have a significant 
Table 5

Indirect effects.

\begin{tabular}{|c|c|c|c|c|c|c|c|c|c|c|c|c|}
\hline & \multicolumn{4}{|c|}{$\begin{array}{l}\text { Neutral third-party information vs. } \\
\text { Control group }\end{array}$} & \multicolumn{4}{|c|}{$\begin{array}{l}\text { Favorable vs. Neutral third-party } \\
\text { information }^{c}\end{array}$} & \multicolumn{4}{|c|}{$\begin{array}{l}\text { Favorable third-party information vs. } \\
\text { Control group }^{\mathrm{d}}\end{array}$} \\
\hline & \multirow[b]{2}{*}{ Effect } & \multirow[b]{2}{*}{ SE (boot) } & \multicolumn{2}{|c|}{$\mathrm{Cl}^{\mathrm{e}}$} & \multirow[b]{2}{*}{ Effect } & \multirow[b]{2}{*}{$\overline{\mathrm{SE} \text { (boot) }}$} & \multicolumn{2}{|c|}{$\mathrm{CI}^{\mathrm{e}}$} & \multirow[b]{2}{*}{ Effect } & \multirow[b]{2}{*}{$\overline{\mathrm{SE} \text { (boot) }}$} & \multicolumn{2}{|c|}{$\mathrm{CI}^{\mathrm{e}}$} \\
\hline & & & Lower & Upper & & & Lower & Upper & & & Lower & Upper \\
\hline through competence trust (H5) & 0.0708 & 0.05 & 0.0105 & 0.1325 & 0.0323 & 0.05 & -0.0253 & 0.1025 & 0.1031 & 0.06 & 0.0298 & 0.1848 \\
\hline through goodwill trust $(\mathbf{H 6})$ & 0.0027 & 0.06 & -0.0723 & 0.0967 & 0.0805 & 0.06 & 0.0080 & 0.1620 & 0.0832 & 0.06 & 0.0121 & 0.1620 \\
\hline
\end{tabular}

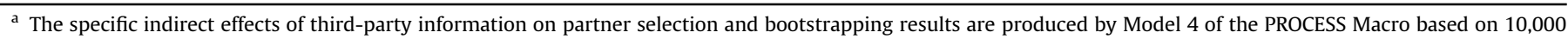
bootstrap samples.

b Represents the effects of neutral third-party information relative to the control condition.

c Represents the effects of favorable third-party information relative to neutral third-party information.

d Represents the effects of favorable third-party information relative to the control condition.

e $80 \%$ Confidence Intervals are reported to indicate whether an effect is significant at the 0.10 level (one-tailed).

positive effect on partner selection, lending support for $\mathrm{H} 3$ and $\mathrm{H} 4$.

$\mathrm{H} 5$ and $\mathrm{H} 6$ further propose that third-party information has an indirect effect on partner selection via its influence on trust. Of particular interest are the specific mediating roles of both competence and goodwill trust in the relationship between our thirdparty information treatments and the likelihood to select. To test for multiple mediation, we follow the recommendations by Preacher and Hayes (2008), using the bootstrap method. ${ }^{17}$ The results are summarized in Table $5 .^{18}$

The indirect effects tests reveal that, for neutral third-party information, the effect is significant through competence trust $(0.07$; $\mathrm{CI}[0.01,0.13])$ but not through goodwill trust $(0.00 ; \mathrm{CI}[-0.07,0.10])$, which is in line with our expectations. Those in the neutral thirdparty information condition are found to be more likely to select on average than those in the control condition, particularly as a result of the indirect mechanism linking neutral third-party information to partner selection through competence trust. Considering favorable third-party information relative to neutral third-party information, the indirect effect through competence trust is not significant $(0.03 ; \mathrm{CI}[-0.03,0.10])$, but reaches significance through goodwill trust $(0.08 ; \mathrm{CI}[0.01,0.16])$. Furthermore, favorable thirdparty information, relative to the control condition, results in a significant indirect effect through both competence trust $(0.10 ; \mathrm{CI}$ $[0.03,0.18])$ and goodwill trust $(0.08 ; \mathrm{CI}[0.01,0.16])$. The signs of the path coefficients and indirect effects are consistent with the interpretation that favorable third-party information, in comparison to having no third-party information at all, enhances both

\footnotetext{
17 The literature on mediation analysis has recommended this as the preferred inferential method; it is considered more valid and powerful than the standard Sobel test, especially for small samples.

18 Significance tests of each indirect effect were accomplished via bootstrapping procedures that created an $80 \%$ confidence interval around the indirect effect estimates. Since we have directional predictions for all indirect effects, we use $80 \%$ confidence intervals to test whether one-tailed p-values are (at least) less than 0.10 i.e., the reported confidence intervals that do not include zero reflect significant indirect effects at the $\mathrm{p}<0.10$ level on a one-tailed basis.

19 This analysis also yields a quantification of the direct effect (path c') and total effect (path c) of third-party information on partner selection. Note, however, that there does not need to be a significant effect to be mediated for the indirect effect to be significant, as is the case for neutral third-party information through competence trust (i.e., the total effect is not significant but the indirect effect is). Fo favorable third-party information, we find the effect on partner selection to be fully mediated by competence trust and goodwill trust, given that the significance of the effect disappears after inclusion of the trust mediators (i.e., the total effect is significant whereas the direct effect is not)

20 Regarding the covariate, trust disposition has a significant positive influence on both trust dimensions, although it is mostly conducive towards goodwill as compared to competence trusting beliefs. The model also allows disposition to trust impacting partner selection directly but, consistent with prior research (e.g. McKnight et al., 2002), this relation is found to be weak because it is largely
} mediated by trusting beliefs. competence trust and goodwill trust, which in turn increases the likelihood of the supplier being selected. Thus, overall we find that third-party information affects partner selection indirectly, through the specific mediating roles of competence trust and goodwill trust, in support for $\mathrm{H} 5$ and $\mathrm{H} 6 .{ }^{1920}$

Having established that there are varying degrees of third-party influence, we now turn to the issue of own prior experience modifying these effects. Recall that $\mathrm{H} 7$ and $\mathrm{H} 8$ predict a negative interaction between third-party information and prior experience. More specifically, support for the proposed substitutional effects requires that both third-party information and prior experience affect trusting beliefs, but with their joint effect being weaker than the sum of their independent effects (see also, Schwab, 2007). ${ }^{21}$ The results in Table 4, however, show no significant interactions for either competence trust or goodwill trust. While, in addition to the aforementioned effects of third-party information, results indicate a positive association between prior experience and the two trust dimensions, we are unable to find evidence that a firm's own prior experience moderates the effect of third-party information on competence trust or goodwill trust.

According to Hayes (2015), a non-significant interaction in the above analysis does not imply that the indirect effect of third-party information on partner selection cannot be moderated by prior experience. We, therefore, proceed with a formal test of moderated mediation, as postulated in $\mathrm{H} 9$ and $\mathrm{H} 10$. The conditional indirect effects and inferential tests using bootstrapped confidence intervals are reported in Table 6.

The indirect effect of neutral third-party information on partner selection through competence trust is positive and significant when prior experience is absent $(0.10 ; \mathrm{CI}[0.01,0.21])$, but not when it is present $(0.05$; CI $[-0.04,0.11])$. Thus, neutral third-party information appears to be particularly helpful in forming competence trusting beliefs when the buyer firm has no prior experience with the supplier and there are no other cues available to inform partner selection decisions. Inspection of the index of moderated mediation, which is the difference between the conditional indirect effects (Hayes, 2015), however, yields a non-significant result as the confidence interval includes zero $(0.05 ; 90 \% \mathrm{CI}[-0.27,0.07]$; untabulated). Based on this, we cannot definitely say that the indirect effect of neutral-third party information through competence trust is altered by prior experience. Further, there is no evidence that favorable third-party information, as compared to neutral thirdparty information, indirectly affects partner selection through

\footnotetext{
21 Based on our theory, this applies to neutral and favorable third-party information for competence trust, whereas for goodwill trust the effect of neutral thirdparty information is not expected and thus mainly relates to the effect of favorable third-party information. For completeness, we do report all interaction effects,
} consistent with the coding systems outlined above. 


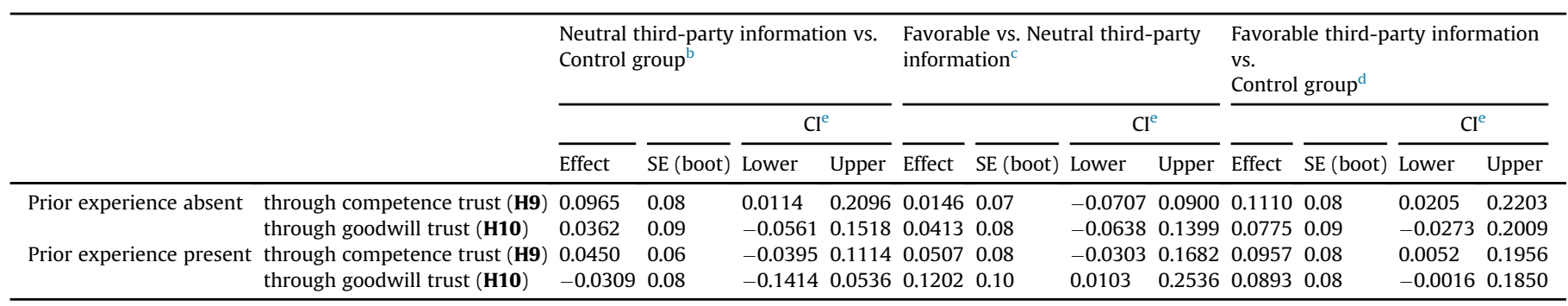

\footnotetext{
bootstrap samples.

b Represents the effects of neutral third-party information relative to the control condition.

c Represents the effects of favorable third-party information relative to neutral third-party information.

d Represents the effects of favorable third-party information relative to the control condition.

e $80 \%$ Confidence Intervals are reported to indicate whether an effect is significant at the 10 percent level (one-tailed).
}

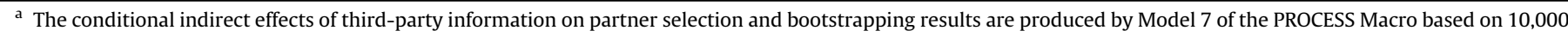

competence trust, irrespective of prior experience. Compared to the control condition, the indirect effect of favorable third-party information on partner selection through competence trust is significant in the absence $(0.11 ; \mathrm{CI}[0.02,0.22])$ and in the presence $(0.10$; CI $[0.01,0.20])$ of prior experience. This observation contradicts the view that third parties are more influential in the absence of own prior experience and that own prior experience, if available, would substitute for third-party information. As favorable thirdparty information continues to have an impact when prior experience is present, this indicates that receiving similar consistent information from different sources is not entirely redundant.

For goodwill trust, we observe that neutral third-party information does not affect partner selection, regardless of prior experience. This is in line with our expectations since third-party experience, without knowing the outcomes, is not expected to mitigate managers' perceptions of relational risk, such that the mediating effect through goodwill trust does not have grounds to exist. Notably, the effect of favorable third-party information on partner selection, as compared to the neutral condition, through goodwill trust is significant when prior experience is present $(0.12$; CI $[0.01,0.25])$, but not when it is absent $(0.04$; CI $[-0.06,0.14])$. Likewise, the effect of favorable third-party information, compared to the control condition, is close to significance when prior experience is present, with the bulk of the confidence interval being above zero $(0.09$; $\mathrm{CI}[-0.00,0.19])$, whereas it is not when prior experience is absent $(0.08 ; \mathrm{CI}[-0.03,0.20])$. This reflects a pattern that is opposite to our expectations, suggesting that, primarily among those with prior experience, favorable third-party information is incorporated in goodwill trust judgments and, subsequently, influences partner selection. Intuitively, this finding is reasonable in that behavioral uncertainties about an unknown partner could be perceived to be too large to allow for reliance on third-party information, and that this information only contributes to goodwill trust once the buyer establishes a baseline of experience with the supplier. Yet again, the indices of moderated mediation indicate that the differences in indirect effects, in itself, are not significantly different, not when compared to the neutral thirdparty information condition $(0.08$; $90 \% \mathrm{CI}[-0.10,0.32]$; untabulated) nor to the control condition $(0.01 ; 90 \% \mathrm{CI}[-0.19,0.20]$; untabulated). As such, we cannot conclude that prior experience is significantly moderating the mediation of favorable third-party information on partner selection via goodwill trust.

Overall, while the moderated mediation analyses reveal interesting insights, they do not univocally support the proposed substitutional effects. Based on the above findings, there is no conclusive evidence that information from own prior experience alters the buyer manager's response to third-party information in the partner selection process. Rather, it seems that own firm's experience with the partner, combined with third-party information, leads to an assessment of the partner's trustworthiness, and influences selection decisions accordingly.

\section{Discussion and conclusion}

In this study, we developed theory and provided evidence that interfirm partnering is affected by a process of trust transfer, in which managers inform their own trusting beliefs and subsequent selection decisions based on the actions and experiences of other firms.

The study contributes to accounting research as it is one of the first to systematically investigate the effects of third-party information in the partner selection process. Extant literature on partner search and selection has mainly focused on the effects of prior partner experience at the level of the dyad (e.g., Dekker, 2008; Dekker \& Van den Abbeele, 2010), while we know little about the role of third parties in the formation of interfirm relationships. Consistent with the notion of trust transfer, we argue that buyers go beyond the dyad when assessing the appeal of a potential supplier, highlighting the value of third parties in that they can diffuse trustrelevant information. In doing so, our study complements recent work on trust development and partner selection, pointing out that potential partners are often evaluated based on external information such as their reputation and others' referral or recommendations (e.g., Ding et al., 2013; Mahama \& Chua, 2016). However, in addition to the influence that third parties have by sharing their experiences and releasing information about past performance, this study implies that the mere observation of other firms' patterns of ties can elicit trust and influence partner selection.

This study's contribution further stems from its fine-grained approach in considering the dimensionality of the trust construct. Building on prior studies (e.g., Anderson et al., 2017; Dekker et al., 2013), we do not only provide further evidence on the existence of competence trust and goodwill trust as two distinct dimensions, but also demonstrate that the two types of trust are unique in their sensitivity to information originating from third parties. By explicitly modeling and measuring these effects, this study contributes to our understanding of how third parties affect partner selection via shaping specific trusting beliefs. Our mediation model confirms two trust-based cognitive mechanisms through which the effect of third-party information on partner selection decisions can be explained.

Most interestingly, both neutral and favorable third-party 
information affect individuals' trust perceptions towards the supplier, but with differential impact given the particular type of trust that it elicits. The key difference is that competence trust is concerned with the partner's ability to perform as expected, not the intention to do so. A very competent firm may well decide to be opportunistic and, therefore, managers need to be mindful of the possibility of a betrayal of trust. If these concerns are at play, one may not be willing to fully trust, without previous evidence of the other party's cooperative intent. In this sense, our observations resonate with a cautious, rational choice approach to trusting (see also, Kramer, 1999; Vosselman \& Van der Meer-Kooistra, 2009), where managers do not make exaggerated evaluations of a trusted party's trustworthiness based on minimal information. Only when it is explicitly known that other firms had satisfactory past dealings with the supplier, this is found to provide sufficient confidence in the supplier's good intentions, in addition to its ability to perform. As such, our results suggest that individuals trust potential suppliers differently depending on the content of available third-party information, and that competence trust is more readily transferred across relationships than goodwill trust.

In addition, we investigate when third-party information is most likely to influence the partner selection process by examining the moderating effect of the focal firm's own prior experience. Our expectation was that unfamiliar firms have less information available from their own experience and thus should pay more attention to signals from others as a main information source. A reduced need for additional information in the presence of own prior experience fits well with explanations of earlier studies for the finding that firms with prior ties invest less time in partner search for new transactions, referring to a preference for known partners, and increased familiarity and trust (e.g., Baum et al., 2005; Dekker \& Van den Abbeele, 2010). Yet, while our results support that prior experience largely contributes to placing trust in the partner, it does not negate the influence of third-party information. Besides consulting information from own experience, if available, it turns out that individuals draw on third parties to inform their trust judgments and subsequent partner selection decisions.

Understanding the different trust cues attended to in nascent relationships also has important practical implications. With improved understanding, these cues can be effectively accounted for in the partner selection process, from the perspective of the initiating as well as the target firms. Initiating firms could build information systems, as to help managers in the assimilation of information about various aspects of potential partners. Considering the focal firm's own prior experience, it is important to make relevant information about past interactions accessible to the respective buyer managers in charge of new collaborations. Given the additional importance of other firms' experiences, firms may also want to seek external validation and proactively collect suggestions from third parties who are knowledgeable about the partner firm, such that a more comprehensive evaluation can be made before a partner is eventually decided on. From the other side, target firms could take actions or develop strategies that facilitate the transfer of trust. Based on our findings, it is in the interest of target firms to provide information about their partnership history and to advertise themselves by emphasizing their experience relevant to the objectives of a new partnership context. Going a step further, they could solicit a testimonial from previous partners to act as reviews. In doing so, they may convince unknown others that they have the appropriate abilities and intentions, in advance of their demonstration of these. And even if they have shown consistent competent performance and commitment in earlier working relationships, such third-party endorsements could accentuate existing competence as well as goodwill trusting beliefs and, in turn, positively influence partner selection decisions for new deals.
While this study reveals interesting findings, it should be interpreted in the light of its bounded scope and also suggests several avenues for further research. In the current setting, we only considered the effect of neutral or positive third-party information. Also, since the pointed information from own firm's and other firms' experiences are both based on positive experience, they are complementary by nature. It would be of interest to understand what happens in the situation where information signals are inconsistent. The transference of trust may also be dependent on who the third parties are and how well one knows or trusts the third-party informants themselves to provide credible information. We leave investigating this for further research.

Moreover, the present study examines the evaluation of collaboration partners pertaining only to the partner selection stage. This perspective limits the depth of understanding of what is typically a dynamic, ongoing process. A longitudinal approach that considers different stages of the relationship might provide better insight into the temporal impact of third-party information. Another useful extension of this study would be to develop an experiment in which participants play repeated trust games. Such a design would allow researchers to better track the interplay between different sources of information and, most importantly, to observe actual trust transference processes at work.

Consistent with other studies addressing governance in interfirm settings, researchers may also wish to consider the influence of third-party information on other decisions, besides partner selection. Whether information regarding third parties' trustfulness towards a particular partner also works, for instance, to reduce the effort put into the contractual management of the relationship represents an interesting topic for further research.

In conclusion, this study provides preliminary, yet promising evidence on the role of third parties in trust formation and partner selection in interfirm relationships. Our moderated mediation analysis is a first step towards more detailed models of partner selection. The results underscore the intermediary position of competence trust and goodwill trust in explaining the relationship between third-party information and partner selection, at the same time accounting for the presence of own prior experience. Further research in this area will be useful to deepen our understanding of the determinants as well as the implications of trust in interfirm settings.

\section{Acknowledgements}

We greatly appreciate the guidance and comments of the editor, Ranjani Krishnan, and the two anonymous reviewers. We also thank Henri Dekker, Yee Shih Phua, Filip Roodhooft, Hendrik Slabbinck, David Smith, Alexandra Van den Abbeele, participants at the 2015 ENEAR Summer School, 2016 EAA Annual Congress, 2016 AAA Annual Meeting, 2018 ACMAR, 2018 Conference on New Directions in Management Accounting, as well as research seminar participants at KU Leuven, Erasmus University Rotterdam, Maastricht University, Tilburg University, and the University of New South Wales for their helpful suggestions. We acknowledge the funding received from the Intercollegiate Center for Management Science to support this research.

\section{Appendix A. Supplementary data}

Supplementary data to this article can be found online at https://doi.org/10.1016/j.aos.2019.101081.

\section{References}

Anderson, S. W., Chang, H. F., Cheng, M. M., \& Phua, Y. S. (2017). Getting to know 
you: Trust formation in new interfirm relationships and the consequences for investments in management control and the collaboration. Contemporary Accounting Research, 34(2), 940-965.

Barrera, D., \& Buskens, V. (2007). Imitation and learning under uncertainty: A vignette experiment. International Sociology, 22(3), 367-396.

Baum, J. A., Rowley, T. J., Shipilov, A. V., \& Chuang, Y. T. (2005). Dancing with strangers: Aspiration performance and the search for underwriting syndicate partners. Administrative Science Quarterly, 50(4), 536-575.

Blumberg, B. F. (2001). Efficient partner search: Embedded firms seeking co-operative partners. Journal of Mathematical Sociology, 25(4), 329-354.

Bohnet, I., \& Huck, S. (2004). Repetition and reputation: Implications for trust and trustworthiness when institutions change. The American Economic Review, 94(2), 362-366.

Bstieler, L. (2006). Trust formation in collaborative new product development. Journal of Product Innovation Management, 23(1), 56-72.

Buskens, V., \& Weesie, J. (2000). An experiment on the effects of embeddedness in trust situations: Buying a used car. Rationality and Society, 12(2), 227-253.

Currall, S. C., \& Inkpen, A. C. (2002). A multilevel approach to trust in joint ventures. Journal of International Business Studies, 33(3), 479-495.

Currall, S. C., \& Judge, T. A. (1995). Measuring trust between organizational boundary role persons. Organizational Behavior and Human Decision Processes, 64(2), 151-170.

Das, T. K., \& Teng, B. S. (2001). Trust, control and risk in strategic alliances: An integrated framework. Organization Studies, 22(2), 251-283.

Dekker, H. C. (2004). Control of inter-organizational relationships: Evidence on appropriation concerns and coordination requirements. Accounting, Organizations and Society, 29(1), 27-49.

Dekker, H. C. (2008). Partner selection and governance design in interfirm relationships. Accounting, Organizations and Society, 33(7-8), 915-941.

Dekker, H. C., Sakaguchi, J., \& Kawai, T. (2013). Beyond the contract: Managing risk in supply chain relations. Management Accounting Research, 24(2), 122-139.

Dekker, H. C., \& Van den Abbeele, A. (2010). Organizational learning and interfirm control: The effects of partner search and prior exchange experiences. Organization Science, 21(6), 1233-1250.

Ding, R., Dekker, H. C., \& Groot, T. (2013). Risk, partner selection and contractual control in interfirm relationships. Management Accounting Research, 24(2), 140-155.

Doney, P. M., \& Cannon, J. P. (1997). An examination of the nature of trust in buyerseller relationships. Journal of Marketing, 61(2), 35-51.

Emsley, D., \& Kidon, F. (2007). The relationship between trust and control in international joint ventures: Evidence from the airline industry. Contemporary Accounting Research, 24(3), 829-858.

Ganesan, S. (1994). Determinants of long-term orientation in buyer-seller relationships. Journal of Marketing, 58(2), 1-19.

Glick, S., \& Croson, R. (2001). Reputations in negotiation. In S. J. Hoch, H. C. Kunreuther, \& R. E. Gunther (Eds.), Wharton on making decisions (pp. 177-186). New York: Wiley.

Gulati, R. (1998). Alliances and networks. Strategic Management Journal, 19(4), $293-317$.

Gulati, R., \& Gargiulo, M. (1999). Where do interorganizational networks come from? American Journal of Sociology, 104(5), 1439-1493.

Hayes, A. F. (2015). An index and test of linear moderated mediation. Multivariate Behavioral Research, 50(1), 1-22.

Hayes, A. F., \& Preacher, K. J. (2014). Statistical mediation analysis with a multicategorical independent variable. British Journal of Mathematical and Statistical Psychology, 67(3), 451-470.

Jørgensen, B., \& Messner, M. (2010). Accounting and strategising: A case study from new product development. Accounting, Organizations and Society, 35(2), 184-204.

Kim, D. Y. (2014). Understanding supplier structural embeddedness: A social network perspective. Journal of Operations Management, 32(5), 219-231.

Kramer, R. M. (1999). Trust and distrust in organizations: Emerging perspectives, enduring questions. Annual Review of Psychology, 50(1), 569-598.

Krishnan, R., Miller, F., \& Sedatole, K. (2011). The use of collaborative interfirm contracts in the presence of task and demand uncertainty. Contemporary Accounting Research, 28(4), 1397-1422.

Laan, A., Noorderhaven, N., Voordijk, H., \& Dewulf, G. (2011). Building trust in construction partnering projects: An exploratory case-study. Journal of Purchasing and Supply Management, 17(2), 98-108.
Langfield-Smith, K. (2008). The relations between transactional characteristics, trust and risk in the start-up phase of a collaborative alliance. Management Accounting Research, 19(4), 344-364.

Li, S. X., \& Rowley, T. J. (2002). Inertia and evaluation mechanisms in interorganizational partner selection: Syndicate formation among US investment banks. Academy of Management Journal, 45(6), 1104-1119.

Lieberman, M. B., \& Asaba, S. (2006). Why do firms imitate each other? Academy of Management Review, 31(2), 366-385.

Mahama, H., \& Chua, W. F. (2016). A study of alliance dynamics, accounting and trust-as-practice. Accounting, Organizations and Society, 51, 29-46.

Mayer, R. C., Davis, J. H., \& Schoorman, F. D. (1995). An integrative model of organizational trust. Acadademy of Management Review, 20(3), 709-734.

McCutcheon, D., \& Stuart, F. I. (2000). Issues in the choice of supplier alliance partners. Journal of Operations Management, 18(3), 279-301.

McEvily, B., Perrone, V., \& Zaheer, A. (2003). Trust as an organizing principle. Organization Science, 14(1), 91-103.

McKnight, D. H., Choudhury, V., \& Kacmar, C. (2002). Developing and validating trust measures for e-commerce: An integrative typology. Information Systems Research, 13(3), 334-359.

McKnight, D. H., Cummings, L. L. \& Chervany, N. L. (1998). Initial trust formation in new organizational relationships. Academy of Management Review, 23(3), 473-490.

Nicolaou, A. I., \& McKnight, D. H. (2006). Perceived information quality in data exchanges: Effects on risk, trust, and intention to use. Information Systems Research, 17(4), 332-351.

Nicolaou, A. I., Sedatole, K. L., \& Lankton, N. K. (2011). Integrated information systems and alliance partner trust. Contemporary Accounting Research, 28(3), $1018-1045$

Nooteboom, B. (1996). Trust, opportunism and governance: A process and control model. Organization Studies, 17(6), 985-1010.

Podolny, J. M. (1994). Market uncertainty and the social character of economic exchange. Administrative Science Quarterly, 39(3), 458-483.

Preacher, K. J., \& Hayes, A. F. (2008). Asymptotic and resampling strategies for assessing and comparing indirect effects in multiple mediator models. Behavior Research Methods, 40(3), 879-891.

Preacher, K. J., Rucker, D. D., \& Hayes, A. F. (2007). Addressing moderated mediation hypotheses: Theory, methods, and prescriptions. Multivariate Behavioral Research, 42(1), 185-227.

Rooks, G., Raub, W., \& Tazelaar, F. (2006). Ex post problems in buyer-supplier transactions: Effects of transaction characteristics, social embeddedness, and contractual governance. Journal of Management \& Governance, 10(3), 239-276.

Rousseau, D. M., Sitkin, S. B., Burt, R. S., \& Camerer, C. (1998). Not so different after all: A cross-discipline view of trust. Academy of Management Review, 23(3) 393-404.

Sako, M. (1992). Prices, quality and trust: Inter-firm relations in Britain and Japan. Cambridge: Cambridge University Press.

Schilke, O., \& Cook, K. S. (2013). A cross-level process theory of trust development in interorganizational relationships. Strategic Organization, 11(3), 281-303.

Schwab, A. (2007). Incremental organizational learning from multilevel information sources: Evidence for cross-level interactions. Organization Science, 18(2) $233-251$.

Shah, R. H., \& Swaminathan, V. (2008). Factors influencing partner selection in strategic alliances: The moderating role of alliance context. Strategic Management Journal, 29(5), 471-494.

Stewart, K. J. (2003). Trust transfer on the world wide web. Organization Science, $14(1), 5-17$.

Tsai, W., \& Ghoshal, S. (1998). Social capital and value creation: The role of intrafirm networks. Academy of Management Journal, 41(4), 464-476.

Uzzi, B. (1997). Social structure and competition in interfirm networks: The paradox of embeddedness. Administrative Science Quarterly, 42(1), 35-67.

Vélez, M. L., Sánchez, J. M., \& Álvarez-Dardet, C. (2008). Management control systems as inter-organizational trust builders in evolving relationships: Evidence from a longitudinal case study. Accounting, Organizations and Society, 33(7), 968-994.

Vosselman, E. \& Van der Meer-Kooistra, J. (2009). Accounting for control and trust building in interfirm transactional relationships. Accounting, Organizations and Society, 34(2), 267-283.

Wittek, R. (2001). Mimetic trust and intra-organizational network dynamics. Journal of Mathematical Sociology, 25(1), 109-138. 